PONTIFÍCIA UNIVERSIDADE CATÓLICA DO RIO DE JANEIRO

\title{
Estudo sobre a Viabilidade Econômica de uma Cervejaria Artesanal no Brasil
}

\author{
João Saldanha Fiuza
}

Trabalho de Conclusão de Curso

Centro de CIÊnCIAS Socials - CCS

DEPARTAMENTO DE ADMINISTRAÇÃO

Graduação em Administração de Empresas 
João Saldanha Fiuza

\title{
Estudo sobre a Viabilidade Econômica de uma Cervejaria Artesanal no Brasil
}

\author{
Trabalho de Conclusão de Curso
}

Trabalho de Conclusão de Curso, apresentado ao programa de graduação em Administração da PUC-Rio como requisito parcial para a obtenção do titulo de graduação em Administração.

Orientador: Rafael Igrejas

Rio de Janeiro

Dezembro de 2017. 


\section{Resumo}

Saldanha Fiuza, João. Estudo sobre a Viabilidade Econômica de uma Cervejaria Artesanal no Brasil. Rio de Janeiro, 2017. 34 p. Trabalho de Conclusão de Curso - Departamento de Administração. Pontifícia Universidade Católica do Rio de Janeiro.

A motivação para a elaboração deste trabalho é o constante crescimento do mercado cervejeiro artesanal ao longo dos anos no Brasil. Hoje este segmento representa em torno de $1 \%$ do total de cervejas comercializadas no país, mas nos EUA por exemplo, onde este mercado já é estabelecido, a representação chega a $20 \%$. Com esta perspectiva, pode-se dizer que ainda há espaço para crescer até que o mercado atinja o seu potencial no Brasil. Considerando esta situação, a partir do levantamento de dados, foi analisada a viabilidade em termos financeiros de operar uma cervejaria artesanal no Brasil ao longo de 20 anos. Para isso, foi utilizada a metodologia de Fluxo de Caixa Descontado, e os principais indicadores utilizados são o Valor Presente Líquido (VPL), Taxa Interna de Retorno (TIR) e Payback Descontado.

Palavras- chave

Cerveja, Cervejaria Artesanal, Valuation, Fluxo de Caixa Descontado 


\section{Abstract}

Saldanha Fiuza, João. Study on the Economic Viability of a small-scale brewery in Brazil. Rio de Janeiro, 2017. 34 p. Trabalho de Conclusão de Curso - Business Administration Department. Pontifícia Universidade Católica do Rio de Janeiro.

The motivation for the elaboration of this work is the constant growth of the craft brewery market over the years in Brazil. Today this segment represents around $1 \%$ of the total beer sold in the country, but in the US, for example, where this market is already established, the representation reaches $20 \%$. From this perspective, it can be said that there is still room to grow until the market reaches its potential in Brazil. Considering this situation, in addition of the data collection, it was analyzed the viability in financial terms to operate a craft brewery in Brazil over 20 years. The methodology used was the Discounted Cash Flow, and the main indicators used are Net Present Value (NPV), Internal Rate of Return (IRR) and Discounted Payback.

Key-words

Beer, Craft Brewery, Valuation, Discounted Cash Flow 


\section{Sumário}

1 O tema e o problema de estudo 1

1.1. Introdução ao tema e ao problema do estudo 1

1.2. Objetivo do estudo 2

1.3. Objetivos intermediários do estudo 2

1.4. Delimitação e foco do estudo 2

1.5. Justificativa e relevância do estudo 2

2 Contexto Mercado Cervejeiro 4

2.1. Produção de Cerveja no Brasil 4

2.2. Mercado Artesanal de Cervejas 6

2.3. Processo de Produção 6

3 Revisão Bibliográfica 9

3.1. Fluxo de Caixa Descontado 9

3.2. Taxa de Desconto 10

3.2.1. Custo do Capital Próprio 10

3.2.2. Custo Médio Ponderado de Capital 11

3.3. Valor Presente Líquido (VPL) 11

3.4. Taxa Interna de Retorno (TIR) 12

$\begin{array}{lr}\text { 3.5. Payback } & 12\end{array}$

4 Estudo de Caso de uma Microcervejaria 14

4.1. Premissas de Investimento e Produção 14

4.2. Projeção de Receitas 16

$\begin{array}{ll}\text { 4.2.1. Demanda } & 16\end{array}$

4.2.2. Preço Médio 17

$\begin{array}{lr}\text { 4.2.3. Receita Adicional } & 18\end{array}$

$\begin{array}{lr}\text { 4.2.4. Receita Projetada } & 19\end{array}$

4.3. Projeção de Custos e Despesas 20

$\begin{array}{ll}\text { 4.3.1. Tributação } & 21\end{array}$ 
4.3.2. Custo da Mercadoria Vendida 21

4.3.3. Despesas 22

4.3.4. Depreciação 23

4.4. Custo de Capital 23

4.4.1. Custo do Capital Próprio (CAPM) 23

4.4.2. Custo do Capital de Terceiros 25

4.4.3. Custo Médio Ponderado de Capital 25

4.5. Projeção de Resultados 26

4.5.1. Fluxo de Caixa dos Ativos 26

4.5.2. Indicadores Financeiros $\quad 27$

4.5.3. Cenário Alternativo 29

5 Conclusões e Recomendações para Novos Estudos 31

6 Referências Bibliográficas 33

\section{Lista de figuras}

Figura 1: Produção de Cerveja no Brasil ..................................................... 4

Figura 2: Sazonalidade da Produção de Bebidas (2002 a 2016) ....................... 5

Figura 3: Distribuição da Produção de Cerveja no Brasil.................................. 5

Figura 4: Receita Bruta Cenário Pessimista .................................................. 19

Figura 5: Receita Bruta Cenário Esperado ................................................... 20

Figura 6: Receita Bruta Cenário Otimista .................................................. 20

Figura 7: Evolução do Fluxo de Caixa dos Ativos entre os Cenários ................. 27

Figura 8: Evolução do FCA Descontado Acumulado entre os Cenários ............. 28

Figura 9: Comparação FCA Desc. Acumulado com Cenário Alternativo ............ 30 


\section{Lista de Tabelas}

Tabela 1: Investimento Inicial do Projeto ................................................ 15

Tabela 2: Demanda Inicial (Litros) ........................................................... 16

Tabela 3: Crescimento Anual da Demanda ................................................. 17

Tabela 4: Proporção de Vendas entre Produtos........................................... 17

Tabela 5: Preço de Venda dos Produtos ..................................................... 18

Tabela 6: Preço do Aluguel da Capacidade Ociosa ........................................ 19

Tabela 7: Anexo II do Sistema de Tributação Simples Nacional 2018 ............... 21

Tabela 8: Custo de Produção Unitário da Garrafa .......................................... 22

Tabela 9: Custo da Mercadoria Vendida ...................................................... 22

Tabela 10: Percentual de Despesas sobre Faturamento ................................. 23

Tabela 11: Custo do Capital Próprio (Modelo CAPM) ........................................ 25

Tabela 12: Composição do FCA no Cenário Esperado ................................... 27

Tabela 13: Indicadores de Viabilidade Econômica ............................................. 28

Tabela 14: Indicadores de Viabilidade Econômica com Cenário Alternativo...... 29

\section{Lista de Equações}

Equação 1: Custo de Capital Próprio ............................................................. 10

Equação 2: Custo Médio Ponderado de Capital ............................................. 11

Equação 3: Valor Presente Líquido .......................................................... 12

Equação 4: Taxa Interna de Retorno............................................................... 12

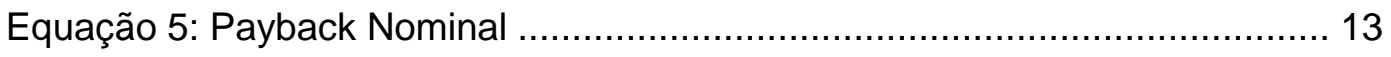

Equação 6: Payback Descontado.......................................................... 13

Equação 7: Valor de Tributação Simples Nacional 2018 ................................ 21

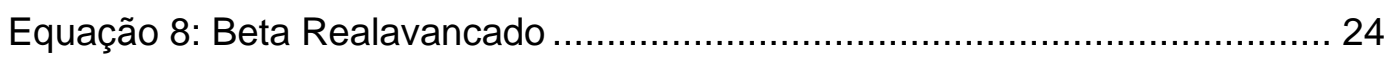

Equação 9: Índice de Conversão US\$/R \$ .................................................. 24 


\section{0 tema e o problema de estudo}

\subsection{Introdução ao tema e ao problema do estudo}

O mercado brasileiro de cervejas apresentou grande crescimento nos últimos anos. De acordo com BNDES (2014), o nível da produção nacional de cerveja aumentou de 9 bilhões de litros em 2005 para 14 bilhões de litros em 2013. De forma complementar, a Associação Brasileira da Indústria da Cerveja (CervBrasil, 2016) indica em seu anuário que o volume do último ano foi de 14,1 bilhões de litros. A concentração de mercado é alta no setor, onde $96 \%$ do mercado corresponde a apenas 3 concorrentes, sendo elas Ambev, Heineken e Grupo Petrópolis (CervBrasil, 2016).

Ainda de acordo com a CervBrasil (2016), a produção de cerveja no Brasil, considerando a sua cadeia produtiva, além de representar $1,6 \%$ do Produto Interno Bruto (PIB) e 14\% da indústria de transformação nacional, é responsável pelo emprego de 2,2 milhões de pessoas em todo o país. A região Sudeste é a mais relevante no cenário nacional, contendo 20 fábricas que produzem $53,8 \%$ do total.

As cervejas artesanais, por sua vez, possuem características diferentes daquelas consideradas tradicionais. São, por definição, produzidas com ingredientes variados e de qualidade, utilizando-se métodos clássicos em pequenas cervejarias (Guia do Gourmet, 2016).

O crescimento anual do segmento é de $20 \%$ a 30\%, de acordo com a Revista Food Magazine (2015). Apesar disso, o mercado artesanal de cervejas representa em torno de $1 \%$ do total atualmente, com tendência de expansão por conta da valorização do produto pelo consumidor (Sebrae, 2016). É natural, portanto, que o setor chame a atenção dos grandes players que hoje dominam o mercado total de cervejas por conta de seu potencial no futuro.

Ao contrário do setor de cervejas como um todo, esse segmento é muito pulverizado, apesar de a maior parte (91\%) ser concentrada nas regiões Sul e Sudeste. Haviam 432 cervejas artesanais no Brasil ao final de 2016, e a expectativa é de 500 ao final de 2017 (Instituto da Cerveja Brasil, 2016).

De acordo com o Mestre-Cervejeiro.com, as cervejas artesanais têm, normalmente, preços mais altos em relação às tradicionais. Este fato pode ser 
explicado principalmente a partir da produção em si, uma vez que há investimento em processos e ingredientes de qualidade, e a tributação, que pode chegar a $60 \%$ do preço pago pelo consumidor final (Mestre-Cervejeiro.com, 2014). Apesar disso, a introdução no sistema Simples Nacional a partir de 2018 pode indicar uma redução significativa na estrutura de custos destes empreendimentos (Revista Beer Art, 2016).

Assim, este trabalho pretende responder à seguinte pergunta: "É economicamente viável iniciar uma microcervejaria hoje no Brasil? ".

\subsection{Objetivo do estudo}

O objetivo final deste estudo é analisar a viabilidade econômico-financeira de uma microcervejaria artesanal no Brasil com base em premissas estabelecidas acerca da situação atual e perspectivas para o futuro do mercado de cerveja artesanal no país.

\subsection{Objetivos intermediários do estudo}

Em primeiro lugar, será fundamental identificar as principais variáveis que influenciam o mercado cervejeiro artesanal, tanto positiva quanto negativamente. A partir disso, definir as premissas para estimar as receitas e gastos do empreendimento.

Em seguida, projetar os fluxos de caixa ao longo do tempo e, por fim, calcular os indicadores financeiros que possibilitarão as análises finais acerca da viabilidade do projeto.

\subsection{Delimitação e foco do estudo}

Este estudo é voltado para o mercado brasileiro de cervejas artesanais, utilizando outros estudos apenas como referências para análises. Em relação ao aprofundamento do conteúdo, as questões terão como foco os impactos financeiros atrelados às variáveis nos cenários traçados. No que diz respeito ao período de projeção do fluxo de caixa, o tempo será de 20 anos.

\subsection{Justificativa e relevância do estudo}

O crescimento do mercado de cervejas artesanais, especialmente quando comparado ao de cervejas em geral, é a principal relevância do tema estudado. 
Ou seja, o potencial do mercado ainda não foi atingido no Brasil, ao contrário de outros países, como os EUA (Sebrae, 2016). Assim, o segmento artesanal é, supostamente, do interesse de investidores e players do mercado de cerveja.

Assim como a maioria dos mercados em ascensão, entretanto, há a necessidade de ultrapassar determinadas barreiras para tornar o negócio mais lucrativo. No caso das cervejarias artesanais, um exemplo é a questão da baixa escala de produção e alto custo, provocados pela qualidade desejada e alta descentralização do segmento. Além disso, a grande incidência de impostos contribui para o aumento de preços e consequente diminuição de competitividade (Mestre-Cervejeiro.com, 2014).

A questão tributária pode, entretanto, ser uma oportunidade a partir de 2018 para o micro cervejeiro, por conta da inclusão na categoria Simples Nacional (Revista Beer Art, 2016). A expectativa é de que esta mudança aumente a rentabilidade das microcervejarias, atraindo mais empreendedores e fomentando ainda mais os negócios do mercado. 


\section{Contexto Mercado Cervejeiro}

\subsection{Produção de Cerveja no Brasil}

Ao analisar a Figura 1 que contém o gráfico do volume total de cervejas no Brasil (BNDES, 2014), é possível perceber a tendência crescente no decorrer dos anos. Entre 2005 e 2013 o volume aumentou cerca de 51\%, o que significa um crescimento médio de $6 \%$ ao ano. Mesmo em períodos de crise e instabilidade econômica, como o ano de 2009, o volume manteve a tendência ascendente.

Atualmente a produção está em torno de 14.100 milhões de litros por ano, de acordo com o anuário da CervBrasil 2016. O faturamento anual do setor é de $R \$ 77$ bilhões, sendo $R \$ 27$ bilhões sendo revertidos em salários para os 2,2 milhões de funcionários e outros $R \$ 23$ bilhões pagos em impostos anualmente. $A$ participação no PIB é de 1,6\% (CervBrasil, 2016).

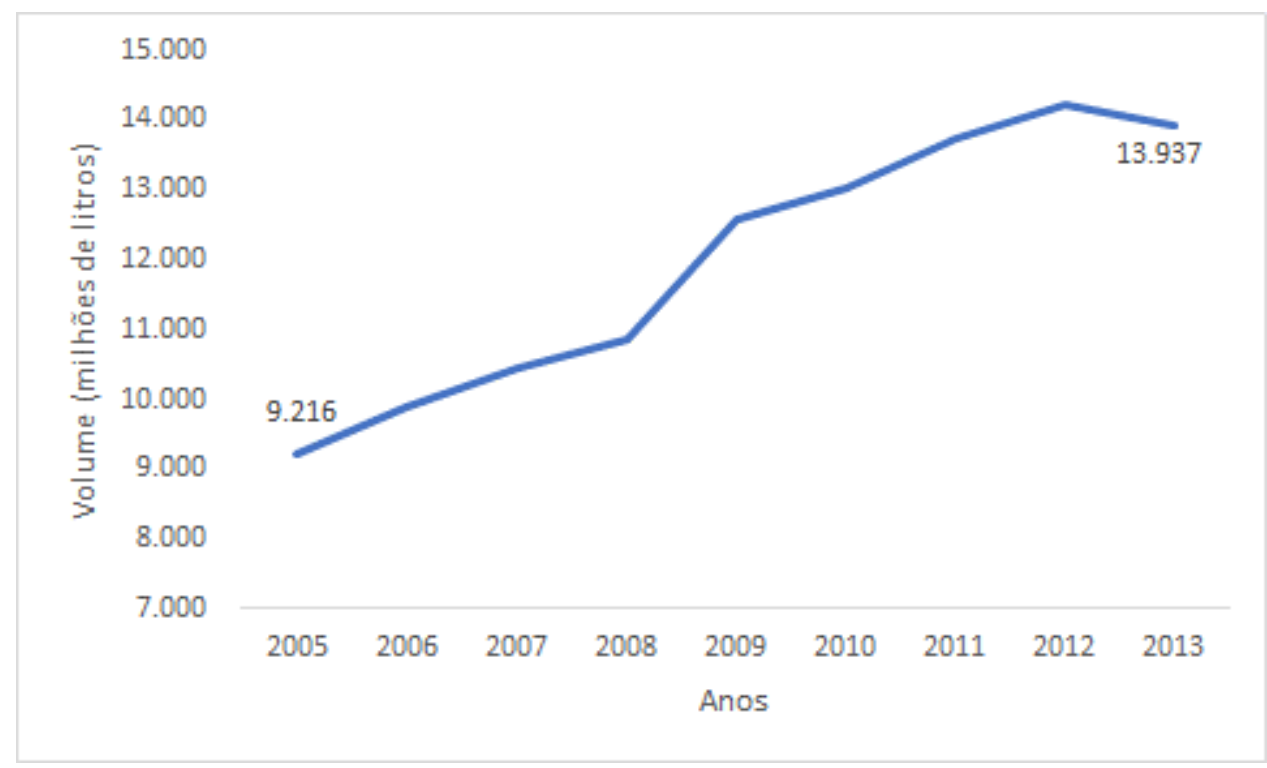

Figura 1: Produção de Cerveja no Brasil

Fonte: BNDES, 2014

Ao longo do ano, entretanto, ocorre uma sazonalidade no setor de bebidas, do qual o mercado de cervejas faz parte. Os números indicam que a maior parte da produção no Brasil acontece em períodos de verão, festas de fim de ano e carnaval (Bradesco, 2017). 


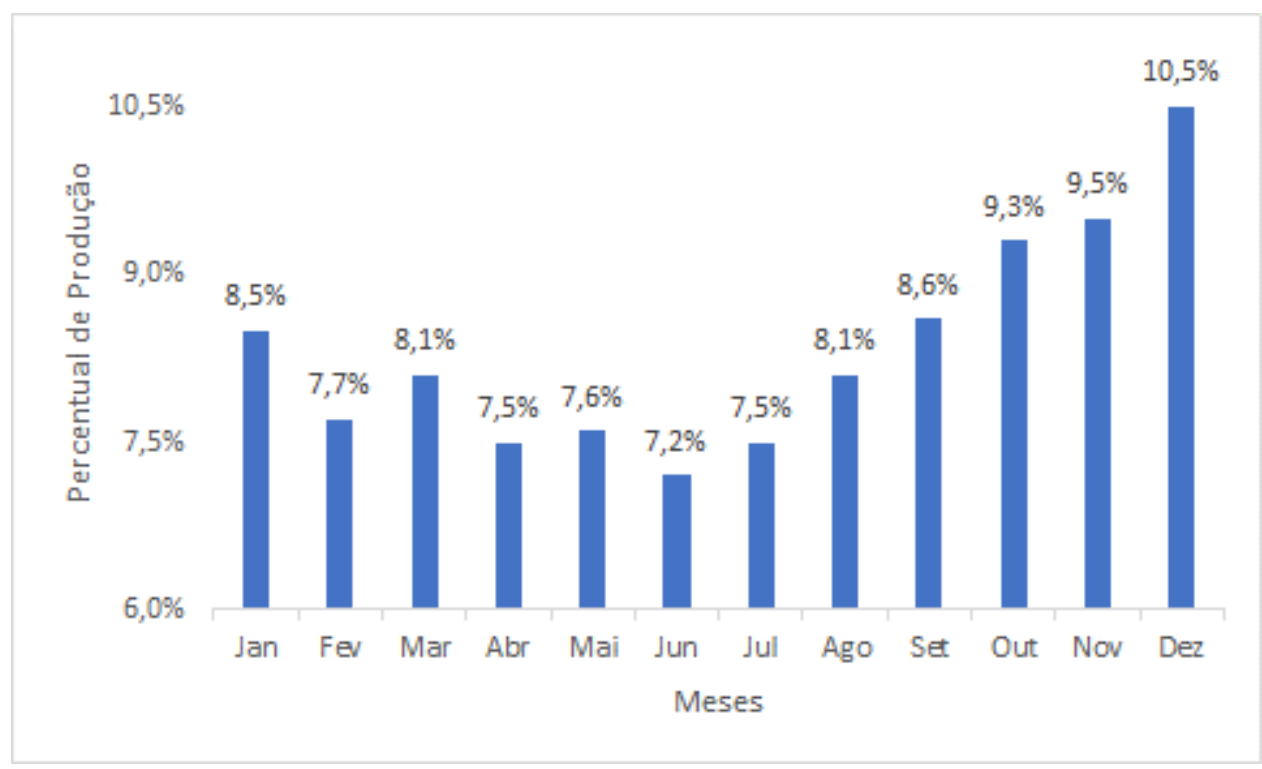

Figura 2: Sazonalidade da Produção de Bebidas (2002 a 2016)

Fonte: Bradesco, 2017

A distribuição das plantas fabris não é uniforme em todo o território brasileiro. De acordo com o anuário da CervBrasil 2016, a maior parte delas está situada na região Sudeste, que possui 20 instalações e é responsável por 53,8\% do volume nacional.

A região nordeste aparece em segundo lugar, com 16 fábricas e 23,2\% do total. O Sul possui 7 fábricas e share de produção de $12,3 \%$, enquanto que 0 Centro-Oeste produz $8,3 \%$ do volume em 4 fábricas. Por fim, a região Norte representa 2,4\% do total com 3 fábricas. A Figura 3 ilustra esta informação.

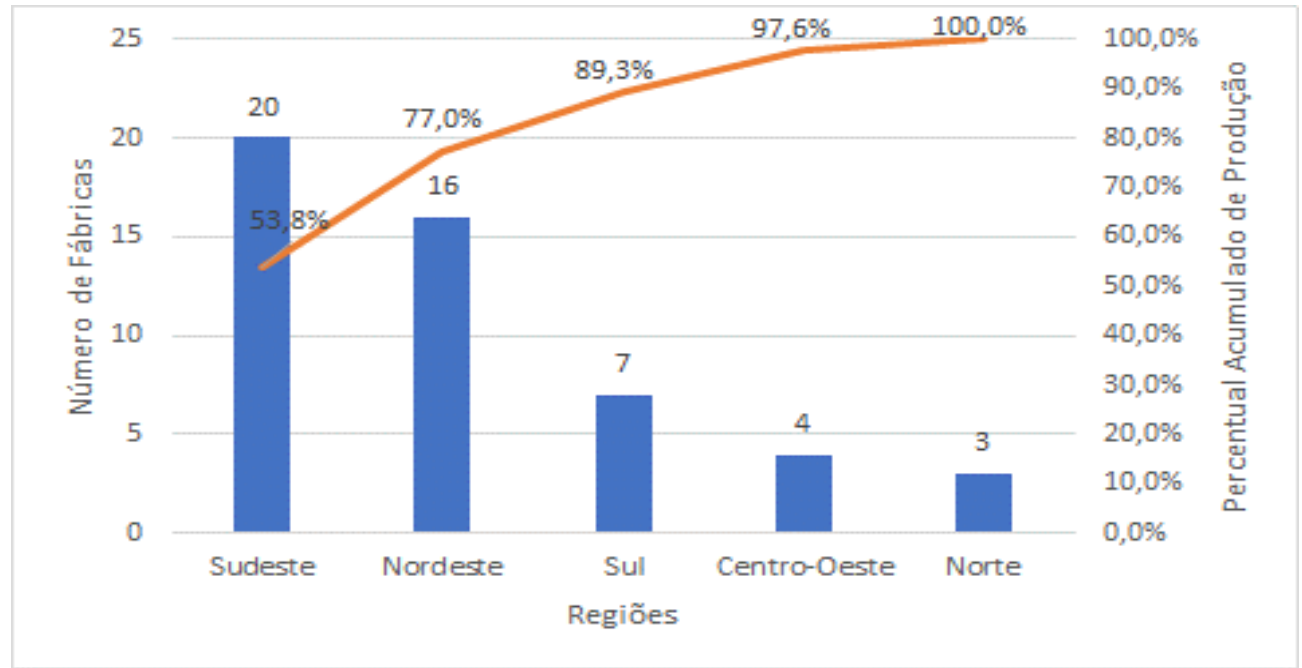

Figura 3: Distribuição da Produção de Cerveja no Brasil Fonte: CervBrasil, 2016 


\subsection{Mercado Artesanal de Cervejas}

As cervejas artesanais, entretanto, possuem características específicas que as diferenciam das demais. O próprio produto também possui variações em relação às cervejas tradicionais, a começar pela seleção de ingredientes e modo de produção. As cervejas artesanais muitas vezes refletem a realidade do local em que são produzidas (Sebrae, 2016).

Essas características são indícios de que há baixa concentração de mercado, e os números do Instituto da Cerveja Brasil (2016) confirmam. A quantidade de cervejarias artesanais em 2016 no Brasil é 432, com crescimento anual de aproximadamente 50 cervejarias, o que equivale a uma nova para cada semana. Há incentivo à variedade e inovação, desde a seleção dos ingredientes, utilizando muitas vezes insumos locais da região onde é produzido, até o processo de fabricação, que gera diferenciação no produto final (Sebrae, 2016).

Considerando o volume médio de produção de 20.000 litros por cervejaria, o volume de cerveja artesanal produzido anualmente é 91 milhões de litros. O percentual sobre o total de cervejas produzidas no Brasil é de 0,7\% (Instituto da Cerveja Brasil, 2016).

Essa análise contribui para indicar que as cervejas artesanais no Brasil ainda não atingiram todo o seu potencial. Nos EUA, por exemplo, as microcervejarias movimentaram cerca de 20 bilhões de dólares em 2014 com 3.418 microindústrias, o que representa aproximadamente $20 \%$ do total (Sebrae, 2016). A expectativa no Brasil é de que a participação das cervejas artesanais aumente de cerca de $1 \%$ para $2 \%$ até 2023.

\subsection{Processo de Produção}

As etapas de produção das cervejas são basicamente as mesmas entre os diferentes estilos. A diferenciação ocorre principalmente em aspectos como a temperatura e tempo de fermentação da bebida, além do ambiente externo, como questões climáticas por exemplo. Os tipos de ingredientes que são selecionados também interferem diretamente na cerveja que está sendo produzida, assim como os equipamentos que são utilizados (Araujo, 2015).

Ao longo do processo de produção da cerveja, a existência de qualquer resíduo ou micro-organismo indesejado pode ser crucial para a qualidade do 
produto final. A limpeza dos equipamentos e insumos deve ser, portanto, a primeira etapa do processo para garantir a boa qualidade (Tostes, 2015).

A principal matéria prima da cerveja são os grãos maltados. Para dar início à produção, é necessário quebrar estes grãos em pedaços menores, que é justamente a moagem. A execução desta etapa está diretamente relacionada à eficiência da produção em relação à utilização dos insumos e consequente variação da qualidade do produto final (Tostes, 2015).

Na etapa de mosturação é obtido o mosto a partir da mistura do malte moído com água, e é submetido a variadas temperaturas e períodos de tempo. A principal finalidade é colocar em contato com a água algumas substâncias presentes no interior dos grãos, para que possam ocorrer as reações necessárias (Instituto da Cerveja Brasil, 2017). Ao final do aquecimento do mosto, é necessário fazer a sua filtração, que é a separação entre a parte líquida e o bagaço do malte. 0 rendimento da produção depende da qualidade do mosto filtrado, ou seja, quanto mais parte líquida melhor (Instituto da Cerveja Brasil, 2017).

O resultado desta filtração deve ser fervido para esterilizar a mistura eliminando os possíveis microrganismos, além de evitar aromas e desenvolver a cor. O nome desse processo é fervura. Nesta etapa é inserido o lúpulo, que é um insumo importante da cerveja, uma vez que a quantidade de lúpulo utilizada é diretamente relacionada ao nível de amargor da bebida (Instituto da Cerveja Brasil, 2017).

O processo de fervura gera uma substância no fundo da panela que deve ser separada. O procedimento utilizado para a separação de substâncias líquidas heterogêneas é a decantação (Araujo, 2015). Para isso é utilizado um aparelho que faz com que o líquido permaneça girando, levando a substância para o fundo e para o centro do equipamento. A partir daí o líquido é retirado lentamente para que o sedimento se mantenha (Instituto da Cerveja Brasil, 2017).

A fermentação acontece com a adição de leveduras, que são o fermento da cerveja. Os açúcares presentes na solução são transformados em álcool e gás carbônico pelas leveduras. Após o período de fermentação, o fermento deve ser retirado e pode ser novamente utilizado em outras produções. Não há adição de álcool de fora para dentro em nenhuma etapa do processo, ele é inteiramente produzido (Instituto da Cerveja Brasil, 2017).

$\mathrm{Na}$ maturação o líquido é aquecido e resfriado com temperatura e tempo variados, e muitas vezes há ainda a adição de outras substâncias, como especiarias, frutas, entre outros. Até mesmo o lúpulo pode ser utilizado novamente para promover um aroma diferenciado (Instituto da Cerveja Brasil, 2017). 
A clarificação é a etapa que tem como finalidade a sedimentação das células de levedura que permanecem na solução a partir da manutenção do líquido em um ambiente de baixa temperatura por um período de no mínimo 4 dias. Por fim, há uma nova filtração para retirar este sedimento. A partir daí o produto é engarrafado, e pode haver, dependendo do estilo e preferência do cervejeiro, um tratamento para esterilizar novamente a bebida, que é chamado de pasteurização (Instituto da Cerveja Brasil, 2017). 


\section{Revisão Bibliográfica}

O objetivo deste capítulo é conceituar de forma teórica a metodologia utilizada para o desenvolvimento do estudo e conclusão a respeito do objetivo proposto. Tendo em vista que neste caso o objetivo é dissertar sobre a viabilidade econômica de uma microcervejaria artesanal, será desenvolvido um valuation para fazer uma análise e chegar a uma conclusão.

Existem diversas formas de calcular o valor de uma empresa. Entretanto algumas metodologias são mais tradicionais, entre elas os Múltiplos de Mercado e o Fluxo de Caixa Descontado (FCD). O primeiro, também conhecido como modelo de avaliação relativa de acordo com Martins (2008), mensura o valor da empresa a partir de comparações com outras.

Para isso, segundo o autor, é necessário que se utilizem parâmetros como o EBITDA, lucro ou patrimônio líquido por exemplo, e sejam empresas similares, para terem números comparáveis. A utilização desta metodologia não é ideal neste estudo por conta da falta de informações financeiras sobre o mercado cervejeiro artesanal e falta de padronização, o que dificulta a comparação entre empresas.

O FCD, por outro lado, dimensiona o valor da empresa a partir da sua própria capacidade de geração de fluxos de caixa no futuro. As características da metodologia fazem com que seja a mais recomendada para este projeto e será detalhada ao longo deste capítulo.

\subsection{Fluxo de Caixa Descontado}

De acordo com Galdi (2008), apud Copeland, Koller e Murrin (2000, p. 66), na técnica do FCD são estimadas as receitas e gastos da empresa que representam a geração de caixa. Posteriormente, os ganhos ou perdas deverão ser ajustados levando em consideração a perda de valor do dinheiro ao longo do tempo e o risco previsto para o investimento. Esta taxa é chamada de taxa de desconto. De acordo com o autor, a metodologia aponta como projetos viáveis aqueles cujo retorno seja maior do que outros investimentos com o mesmo nível de risco. 
Segundo Ross, Westerfield e Jordan (2013), a metodologia pode ser descrita a partir de três etapas. Em primeiro lugar deve ser feita a previsão dos fluxos de caixa que a empresa obterá no futuro. Para isso é necessário traçar premissas financeiras baseadas na expectativa do mercado para algumas variáveis, como a demanda e o seu crescimento ao longo do tempo, por exemplo. A partir disso, esses fluxos de caixa devem ser ajustados a valor presente por meio da taxa de desconto, que reflete o risco e a perda de valor do dinheiro no tempo. Por fim, a conclusão é feita a partir da análise de indicadores baseados nos fluxos de caixa do período estudado. Os principais são o Valor Presente Líquido (VPL), a Taxa Interna de Retorno (TIR) e o Payback, que serão explicados ao longo deste tópico.

\subsection{Taxa de Desconto}

\subsubsection{Custo do Capital Próprio}

Segundo Gitman (2010), o projeto deve retornar ao seu acionista um valor compatível com o que for observado no mercado, além do risco implícito do negócio. Caso contrário, não faria sentido investir no projeto e sim em outras oportunidades com melhores rendimentos.

Assim, o modelo adotado para calcular este retorno é o capital asset pricing model (CAPM). Este modelo busca relacionar o retorno exigido pelos acionistas com o risco atrelado ao mercado. O principal instrumento de adequação é medido por um fator $\beta$, que na prática é um índice que representa a volatilidade do investimento e o risco atrelado ao mesmo.

Sua função no modelo é corrigir a diferença entre o retorno médio do mercado e a taxa livre de risco, também conhecida como prêmio de risco, que é esperada pelo acionista. Para ser utilizado, deve ser desalavancado considerando o endividamento geral do setor e realavancado de acordo com o endividamento do empreendimento.

Quando maior que 1, o investimento é considerado mais volátil e aumenta o prêmio de risco esperado. Quando menor que 1, acontece a situação contrária. A representação algébrica, por sua vez:

$$
C A P M=R_{f}+\left[\beta x\left(R_{m}-R_{f}\right)\right]
$$


Onde:

$\mathrm{R}_{\mathrm{f}}=$ Taxa de juros livre de risco

$\beta=$ Índice de volatilidade e risco atrelado ao negócio

$\mathrm{R}_{\mathrm{m}}=$ Taxa de retorno média do mercado

\subsubsection{Custo Médio Ponderado de Capital}

De acordo com Copeland, Koller e Murrin (2002), é a taxa que deve ser utilizada para descontar os fluxos de caixa futuros e calcular, assim, os respectivos valores presentes. Partindo do princípio de que o primeiro objetivo é retornar o valor investido com os rendimentos mínimos, é possível utilizar o custo médio ponderado de capital (CMPC ou WACC, em inglês) como principal parâmetro.

Para calculá-lo, entretanto, é preciso saber o custo do capital próprio e de terceiros, que é dado pelas condições do empréstimo. Outra informação fundamental é a proporção entre eles em relação ao todo, como pode ser visto na representação algébrica a seguir:

$$
W A C C=\frac{E}{D+E} x C A P M+\frac{D}{D+E} x K d x(1-g)
$$

Onde:

$\mathrm{E}=$ Capital Próprio (equity)

$\mathrm{D}=$ Capital de Terceiros (dívida)

$\mathrm{g}=$ Taxa de Imposto de Renda

$\mathrm{Kd}=$ Custo do Capital de Terceiros

\subsection{Valor Presente Líquido (VPL)}

O conceito básico do VPL segundo Ross, Westerfield e Jordan (2013) é que qualquer investimento tem como objetivo gerar valor para os donos do capital. Se essa condição não for verdadeira para determinado investimento, este não deve ser feito.

De forma prática, os autores afirmam que o valor presente líquido é um indicador para mensurar o valor agregado no presente de um investimento que será realizado no futuro, já considerando os custos envolvidos. Ou seja, para ser aceito, o projeto deve ter VPL maior do que zero. A representação algébrica, por sua vez: 


$$
V P L=\sum_{t=1}^{n} \frac{F C_{t}}{(1+i)^{t}}-I_{0}
$$

Onde:

$\mathrm{i}=$ Taxa de desconto

$\mathrm{n}=$ Número de amostras

$I_{0}=$ Investimento inicial

$\mathrm{t}=$ Tempo em anos

\subsection{Taxa Interna de Retorno (TIR)}

De acordo com Ross, Westerfield e Jordan (2013), a TIR é diretamente relacionada com o VPL. Isso é justificado pelo fato de a TIR ser justamente a taxa que iguala o VPL a zero, e é interna uma vez que considera apenas os fluxos de caixa do projeto.

A limitação de observar única e exclusivamente este indicador é que não se sabe o retorno mínimo exigido para a realização do projeto, que é justamente a taxa de desconto aplicada. Ou seja, se a TIR for maior do que a taxa de desconto, o projeto é aceito, caso contrário deve ser rejeitado. A representação algébrica, por sua vez:

$$
-I_{0}+\sum_{t=1}^{n} \frac{F C_{t}}{(1+T I R)^{t}}=0
$$

\subsection{Payback}

Segundo Ross, Westerfield e Jordan (2013), o período de payback é "o tempo necessário para que um investimento gere fluxos de caixa suficientes para recuperar seu custo inicial". Em outras palavras, é a quantidade de dias, meses ou anos em que o projeto se paga e começa a gerar retorno além do que foi investido para a sua realização.

Para analisar o indicador e tirar conclusões é fundamental estipular o tempo limite aceitável, para servir de comparação. A maior limitação do indicador é não levar em consideração os descontos ao longo do tempo. Por conta disso, é um indicador com relevância contábil, mas não econômica. A representação algébrica, por sua vez: 


$$
\text { Payback }=\text { T quando } \sum_{t=1}^{T} F C_{t}=I_{0}
$$

A utilização mais usual, entretanto, para este indicador é considerando o desconto do custo de capital ao longo do tempo. Ou seja, é o mesmo cálculo, porém com fluxos de caixa descontados.

Esta alteração faz com que o payback descontado seja mais conservador e realista em comparação ao nominal, pois considera o custo do capital que engloba o risco atrelado ao investimento. A representação algébrica, por sua vez:

$$
\text { Payback }=T \text { quando } \sum_{t=1}^{T} \frac{F C D_{t}}{(1+i)^{t}}=I_{0}
$$




\section{Estudo de Caso de uma Microcervejaria}

Neste capítulo serão apresentadas as premissas utilizadas para a projeção dos fluxos de caixa de uma microcervejaria artesanal no Brasil, assim como os resultados financeiros provenientes da sua operação. $O$ objetivo é analisar a viabilidade do negócio, além de ressaltar os principais pontos de atenção que podem aumentar o risco atrelado a ele. Tendo isso em vista, foram considerados 3 cenários de projeção: o esperado e, o pessimista e o otimista.

\subsection{Premissas de Investimento e Produção}

A capacidade de produção instalada inicialmente é de 5.000 litros para cada processo de produção, também conhecido por brassagem. O custo estimado para começar a operar é de $R \$ 1.002 .800,00$, sendo $R \$ 552.800,00$ para máquinas e equipamentos. O restante, equivalente a $\mathrm{R} \$ 450.000,00$, diz respeito à aquisição do terreno, obras necessárias, consultoria e cursos. Os valores foram levantados com base em projetos similares e estão detalhados na tabela 1 a seguir: 
Tabela 1: Investimento Inicial do Projeto

Fonte: Elaborada pelo autor

\begin{tabular}{|c|c|c|c|c|}
\hline Máquinas e Equipamentos & $\mathrm{Cu}$ & to Unitário & Qtd & Total \\
\hline Cozinha $250 \mathrm{~L}$ (Tinas, plataformas etc) & $\mathrm{R} \$$ & $130.000,00$ & 1 & $\mathrm{R} \$ 130.000,00$ \\
\hline Tanque Água Quente 500L & $\mathrm{R} \$$ & $17.000,00$ & 1 & $\mathrm{R} \$ \quad 17.000,00$ \\
\hline Aerador de mosto em linha & $\mathrm{R} \$$ & $1.400,00$ & 1 & $1.400,00$ \\
\hline Tanques Fermentador $250 \mathrm{~L}$ & $\mathrm{R} \$$ & $15.500,00$ & 2 & $\mathrm{R} \$ \mathrm{~S} \quad 31.000,00$ \\
\hline Tanques Fermentador 500L & $\mathrm{RS}$ & $18.000,00$ & 2 & $\mathrm{R} \$ \mathrm{~N} \quad 36.000,00$ \\
\hline Tubulação de mosto frio & $\mathrm{RS}$ & $4.500,00$ & 1 & 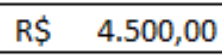 \\
\hline Bomba móvel pra CIP & $\mathrm{R} \$$ & $4.000,00$ & 1 & $4.000,00$ \\
\hline Moedor & $\mathrm{RS}$ & $9.500,00$ & 3 & RS $28.500,00$ \\
\hline Lavadora de barril - sistema automático & $\mathrm{R} \$$ & $39.500,00$ & 1 & $\mathrm{R} \$ 39.500,00$ \\
\hline Envasadora de chope 03 bicos & $\mathrm{R} \$$ & $4.000,00$ & 1 & $\mathrm{R} \$ \quad 4.000,00$ \\
\hline Banco de Gelo 2.000 litros & $\mathrm{R} \$$ & $39.500,00$ & 2 & $\mathrm{R} \$ \mathbf{7 9 . 0 0 0 , 0 0}$ \\
\hline Filtro duplo para água filtrada & $\mathrm{RS}$ & $3.000,00$ & 1 & $\mathrm{R} \$ \quad 3.000,00$ \\
\hline Tubulações e isolamento de ageda & $\mathrm{R} \$$ & $28.800,00$ & 1 & $\mathrm{R} \$ 28.800,00$ \\
\hline Montagem & $\mathrm{RS}$ & $22.000,00$ & 1 & $\mathrm{R} \$ 22.000,00$ \\
\hline Barris de madeira & $\mathrm{RS}$ & $1.500,00$ & 12 & $\mathrm{R} \$ 18.000,00$ \\
\hline Barris de INOX $30 \mathrm{~L}$ & $\mathrm{R} \$$ & 450,00 & 58 & $\mathrm{R} \$ 26.100,00$ \\
\hline Material Taproom & $\mathrm{R} \$$ & $15.000,00$ & 1 & $\mathrm{R} \$ 15.000,00$ \\
\hline Camara Fria & $\mathrm{RS}$ & $15.000,00$ & 1 & $\mathrm{R} \$ 15.000,00$ \\
\hline Tanques Fermentador $3000 \mathrm{~L}$ & $\mathrm{RS}$ & $45.000,00$ & 0 & $\mathrm{R} \$ \quad-$ \\
\hline Lavadora de garrafas & $\mathrm{R} \$$ & $50.000,00$ & 1 & $\mathrm{R} \$ \mathbf{5 0 . 0 0 0 , 0 0}$ \\
\hline TOTAL & - & & - & $\mathrm{RSS} 552.800,00$ \\
\hline
\end{tabular}

\begin{tabular}{|l|rr|}
\hline Demais investimentos & \multicolumn{2}{|c|}{ Custo } \\
\hline Consultoria & $\mathrm{R} \$$ & $60.000,00$ \\
\hline Curso Mestre-cervejeiro & $\mathrm{R} \$$ & $90.000,00$ \\
\hline Aquisição do terreno & $\mathrm{R} \$$ & $150.000,00$ \\
\hline Obra Civil + Arquitetura & $\mathrm{R} \$$ & $150.000,00$ \\
\hline
\end{tabular}

\begin{tabular}{|l|ll|}
\hline Total Investimento Inicial & RȘ & $1.002 .800,00$ \\
\hline
\end{tabular}

A necessidade de novos investimentos para ampliação, entretanto, irá variar de acordo com cada um dos cenários. Isso acontece porque uma simplificação do estudo indica que a quantidade produzida é igual à demanda do período. Como é impossível produzir além da capacidade, a velocidade do crescimento da demanda é um fator essencial para determinar o aumento da capacidade produtiva.

Outra implicação desta premissa é de que não existem custos com estocagem. O custo de ampliação da produção para cada 5.000 litros adicionais já com a fábrica instalada é de $\mathrm{R} \$ 100.000,00$ para aquisição de novos equipamentos. Por fim, foi definido que a capacidade pode ser ampliada duas vezes, limitando a capacidade de produção final ao triplo da inicial. Considerando uma eficiência de $90 \%$ com perda de apenas 10\% da produção e 6 brassagens 
por ano, a capacidade inicial anual real é de 27.000 litros. A final, portanto, é de 81.000 litros.

\subsection{Projeção de Receitas}

Para estimar a receita do empreendimento ao longo dos 20 anos de projeção, foram assumidas premissas em relação à quantidade demandada em litros e ao preço médio de venda na mesma unidade de medida.

\subsubsection{Demanda}

De acordo com especialistas do mercado, no primeiro mês de vendas uma pequena cervejaria consegue vender em torno de 700 litros. Como é preciso um período de aproximadamente um mês desde o início da produção até a finalização da cerveja, o primeiro mês de vendas é o segundo mês de operação. Além dessa condição, por tratar-se de um longo período de projeção, foram assumidas taxas diferentes para cada etapa da empresa: até 5 anos, de 6 a 10 anos e a partir de 11 anos.

Para estimar a velocidade de crescimento em cada etapa, entretanto, foi feito um estudo considerando o crescimento do mercado em torno de $25 \%$ ao ano, segundo a Revista Food Magazine (2015) e o crescimento do número de cervejarias de $16 \%$ ao ano de acordo com o Instituto da Cerveja Brasil. A partir do volume produzido pelo segmento e a quantidade de cervejarias a cada ano, foi definido um market share médio para cada período. Foi aplicada uma porcentagem de atingimento no volume médio de cada ano para ponderar o percentual do volume médio produzido pela empresa a cada ano. As taxas do cenário esperado foram obtidas a partir do crescimento percentual do volume produzido pela empresa. A partir disso, a taxa foi manipulada na mesma proporção de $20 \%$ para cima e para baixo para chegar aos cenários otimista e pessimista.

Para fazer o cálculo da demanda, é aplicada a taxa de crescimento sobre a quantidade demandada no período anterior de acordo com o cenário e o ano projetado, como pode ser visto nas tabelas 2 e 3 a seguir:

Tabela 2: Demanda Inicial (Litros)

Fonte: Elaborada pelo autor

\begin{tabular}{|c|c|c|c|}
\hline Meses & Pessimista & Esperado & Otimista \\
\hline Mês 1 & 0,0 & 0,0 & 0,0 \\
\hline Mês 2 & 700,0 & 700,0 & 700,0 \\
\hline
\end{tabular}


Tabela 3: Crescimento Anual da Demanda

Fonte: Elaborada pelo autor

\begin{tabular}{|l|c|c|c|}
\hline \multicolumn{1}{|c|}{ Tempo } & Pessimista & Esperado & Otimista \\
\hline Até 5 anos & $23 \%$ & $29 \%$ & $35 \%$ \\
\hline Entre 5 e 10 anos & $15 \%$ & $18 \%$ & $22 \%$ \\
\hline Após 10 anos & $6 \%$ & $8 \%$ & $10 \%$ \\
\hline
\end{tabular}

\subsubsection{Preço Médio}

É o preço de venda aplicado em média sobre cada litro de produto comercializado. Portanto, trata-se da média ponderada entre os preços de cada tipo de produto levando em consideração a proporção de venda entre eles. Serão dois tipos de produto: garrafa e chope, e a proporção de vendas entre os tipos também é uma premissa assumida que varia de acordo com os cenários.

Os valores utilizados no cenário esperado foram levantados junto a especialistas do mercado. A variação para os cenários pessimista e otimista é linear $5 \%$ para baixo ou para cima, e estão expostos a seguir, na tabela 4 :

Tabela 4: Proporção de Vendas entre Produtos

Fonte: Elaborada pelo autor

\begin{tabular}{|l|c|c|c|}
\hline \multicolumn{1}{|c|}{ Tipo de Produto } & Pessimista & Esperado & Otimista \\
\hline Chopp $1 \mathrm{~L}$ & $30 \%$ & $25 \%$ & $20 \%$ \\
\hline Garrafa $600 \mathrm{ml}$ & $70 \%$ & $75 \%$ & $80 \%$ \\
\hline
\end{tabular}

É possível perceber que no cenário otimista foi considerada uma proporção maior de venda de garrafas e consequentemente menor de chope. Isso acontece porque a margem de contribuição da garrafa é maior, e, portanto, o tipo de produto mais lucrativo para a empresa. Esta conclusão será detalhada no item sobre "custo de mercadoria vendida", mais adiante.

No que diz respeito ao preço de venda de cada um dos tipos de produto, foi determinado junto a especialistas do mercado que o chope pode ser comercializado a $\mathrm{R} \$ 20,00$, que foi utilizado no cenário esperado. Para o otimista e pessimista, foi considerada uma variação de $10 \%$ para cima e para baixo respectivamente.

Sobre a garrafa, o preço foi calculado com base nos custos envolvidos de acordo com especialistas de mercado aplicando-se um markup. Para o cenário esperado o markup definido foi de $110 \%$, com variações de $10 \%$ para cima e para 
baixo nos cenários otimista e pessimista. Uma informação importante é que o preço é da garrafa que contém $600 \mathrm{ml}$, mas o preço ponderado pela proporção de venda leva em consideração o valor proporcional de um litro do produto. Os resultados estão na tabela 5 a seguir:

Tabela 5: Preço de Venda dos Produtos

Fonte: Elaborada pelo autor

\begin{tabular}{|l|cc|cc|cc|}
\hline \multicolumn{1}{|c|}{ Produto / Média } & \multicolumn{2}{|c|}{ Pessimista } & \multicolumn{2}{c|}{ Esperado } & \multicolumn{2}{c|}{ Otimista } \\
\hline Garrafa (600ml) & R\$ & 17,14 & R\$ & 18,00 & R\$ & 18,85 \\
\hline Chopp (litro) & R\$ & 18,00 & R\$ & 20,00 & R\$ & 22,00 \\
\hline Média Ponderada (litro) & R\$ & 25,40 & R\$ & 27,50 & R\$ & 29,54 \\
\hline
\end{tabular}

\subsubsection{Receita Adicional}

Ao observar a demanda ao longo dos anos e a capacidade de produção instalada, é possível identificar que existe uma parcela que permanece ociosa, uma vez que a capacidade de produção deve ser sempre igual ou maior do que a demanda. Assim, uma outra forma de gerar receita para o empreendimento é o aluguel desta capacidade para outras cervejarias artesanais.

Existem cervejarias que trabalham com esta fonte adicional de receita, como a Serra Verde Imperial. De acordo com artigo do O Globo (2017), a empresa inaugurou uma fábrica em Niterói na qual entre 30\% e 40\% da capacidade de produção é alugado para outros produtores artesanais.

As premissas atreladas à esta fonte de receita são em relação à demanda e preço. Em primeiro lugar, é considerado que $100 \%$ da capacidade ociosa é alugada, ou seja, tudo o que não está sendo utilizado para produção é rentabilizado sob forma de aluguel para terceiros.

O preço por litro, por sua vez, foi calculado com base no custo médio de se produzir cada litro, levando em consideração o investimento nos equipamentos e a sua vida útil de 10 anos. A conta é feita a partir da divisão do investimento realizado pela soma de litros que os equipamentos são capazes de produzir em sua vida útil e será detalhada no item sobre "custo de mercadoria vendida" mais adiante.

A partir desse valor é aplicado o markup que varia de acordo com os cenários. De acordo com especialistas, o custo de locação para os terceiros pode representar cerca de $60 \%$ do preço de venda. De forma conservadora, foi estimado um preço de aluguel por litro que representa em torno de $40 \%$ do preço de venda considerando o preço ponderado do cenário esperado de $R \$ 27,50$ como 
referência. Isso indica que o markup é de $450 \%$, e a variação entre os cenários é de $100 \%$ para baixo ou para cima. A conclusão e valores finais estão na tabela 6 a seguir:

Tabela 6: Preço do Aluguel da Capacidade Ociosa

Fonte: Elaborada pelo autor

\begin{tabular}{|l|c|c|c|}
\hline & Pessimista & Esperado & Otimista \\
\hline Mark Up & $350 \%$ & $450 \%$ & $550 \%$ \\
\hline Valor/Litro & R\$ 9,21 & R\$̦ 11,26 & R\$ 13,31 \\
\hline
\end{tabular}

\subsubsection{Receita Projetada}

A cada período a multiplicação da quantidade demandada pelo preço médio gera a receita proveniente de vendas, e a multiplicação da quantidade ociosa pelo preço de aluguel dá origem à receita de aluguel. A receita total, também conhecida como faturamento bruto, é a soma das duas fontes. A seguir, nas figuras 4,5 e 6 estão os resultados obtidos em cada um dos cenários:

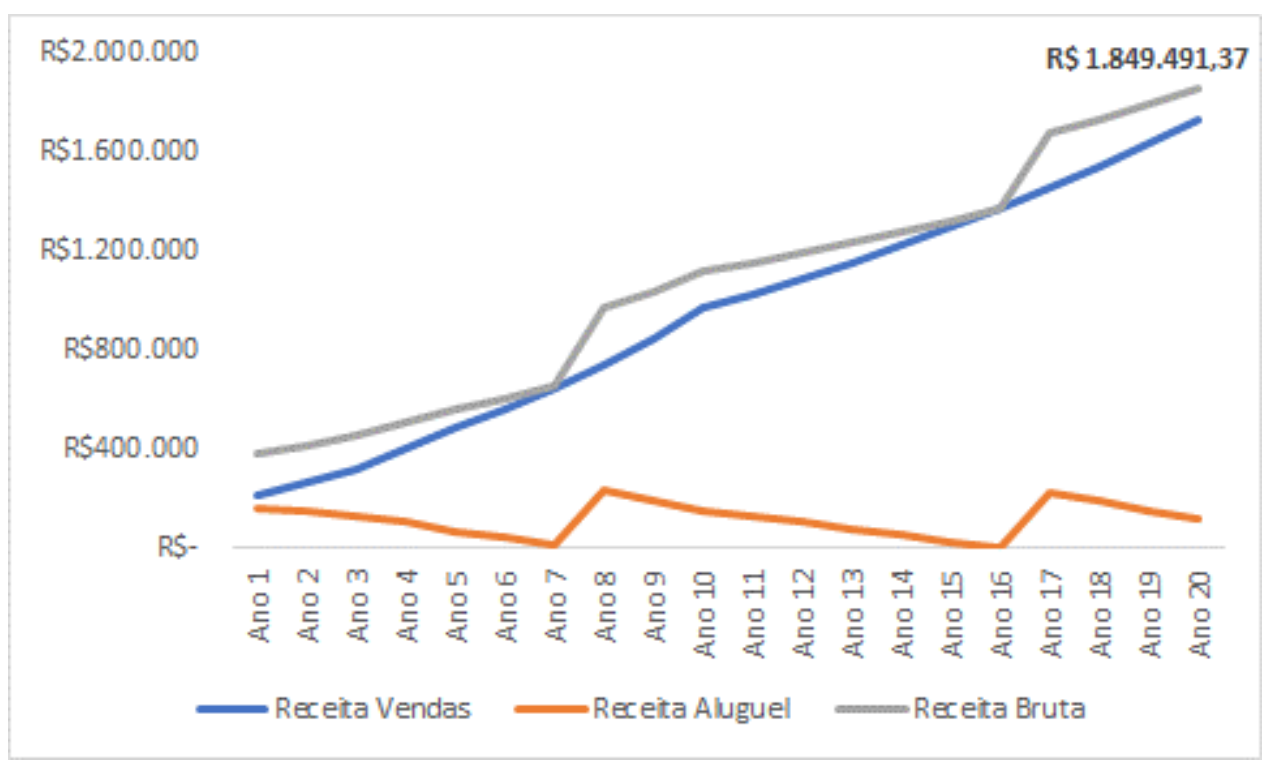

Figura 4: Receita Bruta Cenário Pessimista

Fonte: Elaborada pelo autor 


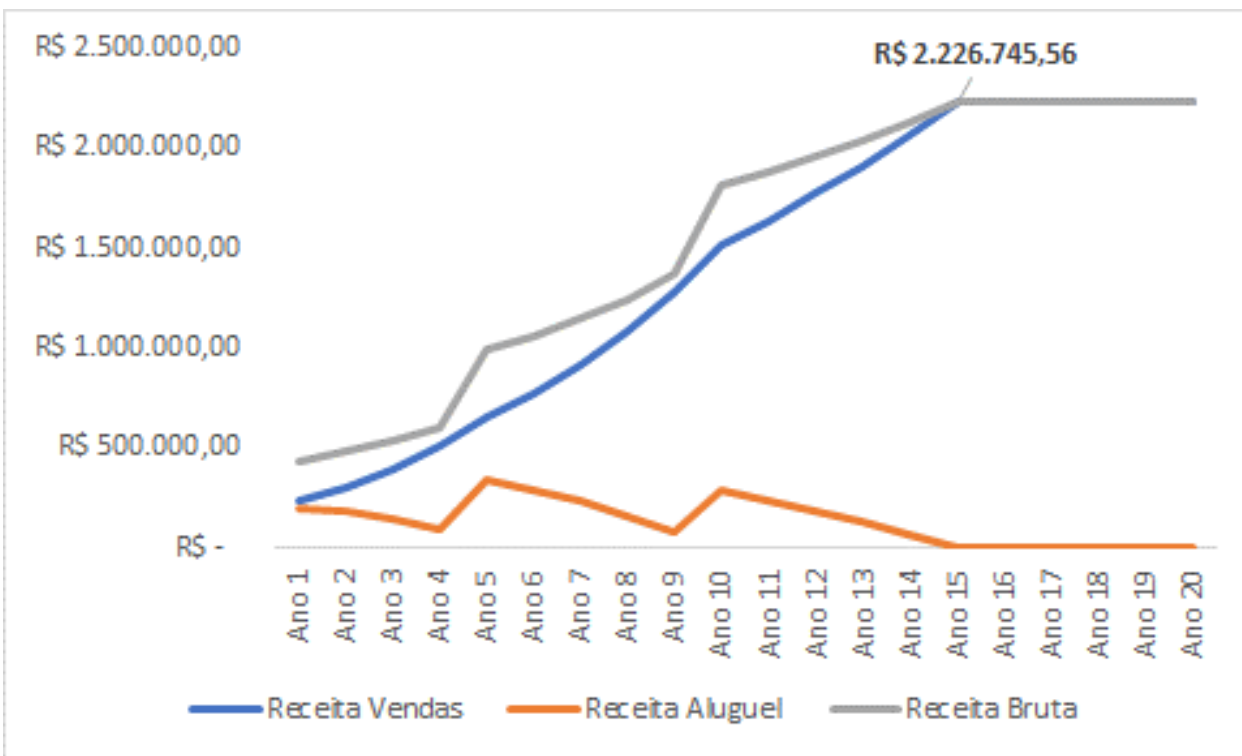

Figura 5: Receita Bruta Cenário Esperado

Fonte: Elaborada pelo autor

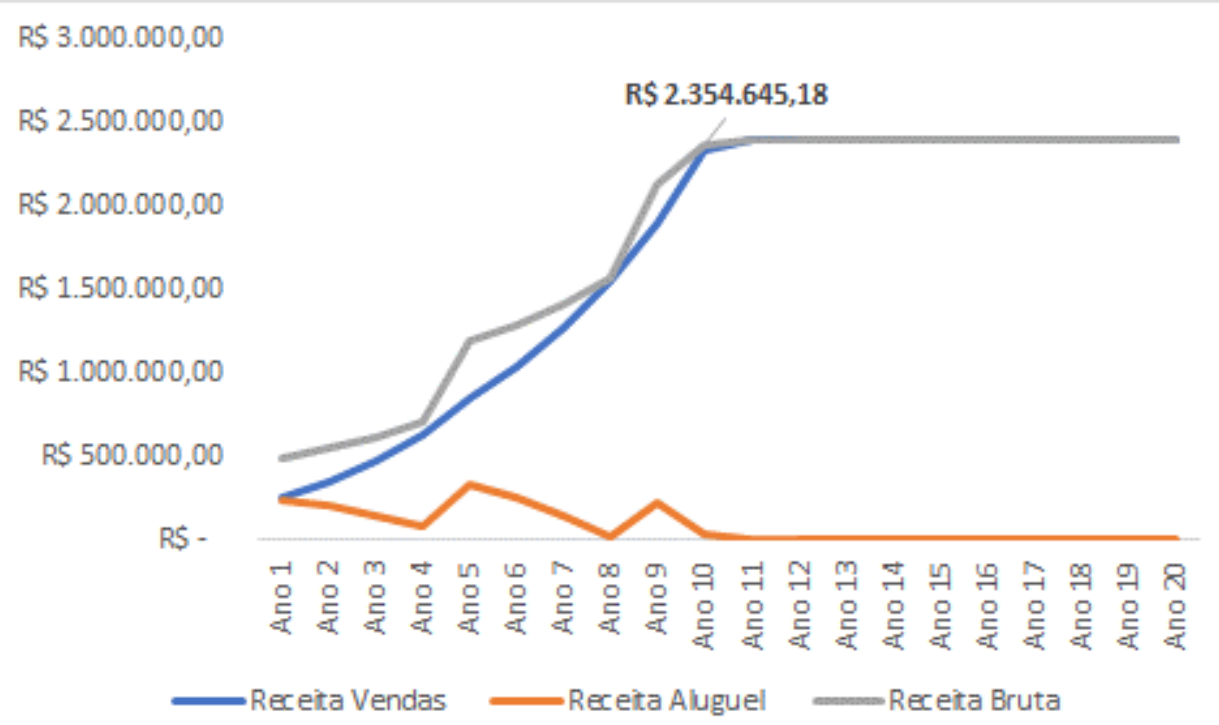

Figura 6: Receita Bruta Cenário Otimista

Fonte: Elaborada pelo autor

\subsection{Projeção de Custos e Despesas}

Neste item serão descritos todos os custos e despesas necessários para a operação de uma microcervejaria. Assim como no caso das receitas, premissas foram traçadas para estimar as saídas de caixa do empreendimento. 


\subsubsection{Tributação}

Levando em consideração o fato já mencionado de que as microcervejarias serão incluídas no sistema de tributação Simples Nacional, a projeção utiliza as regras deste sistema para calcular os gastos com impostos.

De acordo com o Jornal Contábil (2017), as regras sobre inclusão de empresas, limites de faturamento e alíquotas do Simples Nacional serão modificadas a partir de 2018. Segundo o artigo, o faturamento máximo vai aumentar de $\mathrm{R} \$ 3,6$ milhões para $\mathrm{R} \$ 4,8$ milhões e a alíquota será maior, porém com um desconto previsto dependendo da faixa de faturamento da empresa. Estas informações estão descritas na tabela 7 a seguir, referente ao anexo II do Simples Nacional 2018, na qual estão enquadradas fábricas/indústrias e empresas industriais:

Tabela 7: Anexo II do Sistema de Tributação Simples Nacional 2018

Fonte: Jornal Contábil, 2017. Adaptado

\begin{tabular}{|c|cc|cc|c|cr|}
\hline Faixa & \multicolumn{2}{|c|}{ De } & \multicolumn{2}{|c|}{ A } & Taxa & \multicolumn{2}{|c|}{ Desconto } \\
\hline 1 & R\$ & - & R\$ $180.000,00$ & $4,50 \%$ & R\$ & - \\
\hline 2 & R\$ $180.000,01$ & R\$ $360.000,00$ & $7,80 \%$ & R\$ & $5.940,00$ \\
\hline 3 & R\$ $360.000,01$ & R\$ $720.000,00$ & $10,00 \%$ & R\$ $13.860,00$ \\
\hline 4 & R\$ $720.000,01$ & R\$ $1.800 .000,00$ & $11,20 \%$ & R\$ $22.500,00$ \\
\hline 5 & R\$ $1.800 .000,01$ & R\$ $3.600 .000,00$ & $14,70 \%$ & R\$ $85.000,00$ \\
\hline 6 & R\$ 3.600.000,01 & R\$ 4.800.000,00 & $30,00 \%$ & R\$ 720.000,00 \\
\hline
\end{tabular}

A conta a ser feita para calcular a tributação é, portanto:

$$
T_{(f)}=\left(R B \times t_{(f)}\right)-D_{(f)}
$$

Onde:

$T_{(f)}=$ Valor de impostos a pagar em função da faixa de faturamento

$\mathrm{RB}=$ Receita Bruta

$t(f)=$ Taxa de imposto em função da faixa de faturamento

$D_{(f)}=$ Desconto em função da faixa de faturamento

\subsubsection{Custo da Mercadoria Vendida}

Como já foi explicado anteriormente, os dois tipos de produto oferecidos pela cervejaria são garrafa e chope. De acordo com especialistas do mercado, o custo de produzir um litro de chope representa $55 \%$ do seu preço de venda. Estão 
incluídos neste valor a matéria prima e demais custos de produção. Esse percentual foi utilizado na projeção em todos os cenários.

Em relação à garrafa, os custos atrelados à sua produção totalizam $R \$ 8,57$ e dizem respeito ao envase propriamente dito, rotulagem, aquisição da garrafa e tampa. A tabela 8 contém os valores adotados junto a especialistas do mercado, e permanecem constantes em todos os cenários:

Tabela 8: Custo de Produção Unitário da Garrafa

Fonte: Elaborada pelo autor

\begin{tabular}{|l|lr|}
\hline \multicolumn{1}{|c|}{ Itens } & \multicolumn{2}{c|}{ Custo } \\
\hline Envase + Rótulo por garrafa & $\mathrm{R} \$$ & 6,50 \\
\hline Garrafa + Tampa & $\mathrm{R} \$$ & 2,07 \\
\hline
\end{tabular}

Entretanto, ao longo da projeção este valor foi utilizado como um percentual sobre o preço de venda. Como o markup sobre o custo varia de acordo com os cenários, o percentual também sofrerá alterações. A tabela 9 expõe os custos de mercadoria vendida (CMV) em termos percentuais, assim como a sua média ponderada segundo a proporção de venda entre os tipos de produto:

Tabela 9: Custo da Mercadoria Vendida

Fonte: Elaborada pelo autor

\begin{tabular}{|l|c|c|c|}
\hline \multicolumn{1}{|c|}{ Produto / Média } & Pessimista & Esperado & Otimista \\
\hline Garrafa & $50,0 \%$ & $47,6 \%$ & $45,5 \%$ \\
\hline Chopp & $55,0 \%$ & $55,0 \%$ & $55,0 \%$ \\
\hline Média Ponderada & $51,5 \%$ & $49,5 \%$ & $47,4 \%$ \\
\hline
\end{tabular}

A receita de aluguel da capacidade ociosa não possui custos diretos atrelados a ela. Afinal de contas, o investimento nos equipamentos já foi feito e os responsáveis por arcar com custos de produção são os terceiros.

\subsubsection{Despesas}

Além dos custos de produção, para a cervejaria conseguir operar são necessários outros gastos, incluindo as despesas operacionais de vendas, administrativas e investimento em marketing e publicidade. Na projeção os valores são representados em termos de percentual da receita, sendo que os dois primeiros sobre o total bruto e o último apenas sobre a receita de venda de cerveja. 
Isso é feito porque o investimento em propaganda, ao contrário dos demais, remete apenas à venda dos produtos, e não ao aluguel dos equipamentos.

Esses gastos tratam-se da remuneração dos empregados, manutenção de equipamentos e divulgação dos produtos, entre outras despesas rotineiras. A tabela 10 indica os percentuais aplicados:

Tabela 10: Percentual de Despesas sobre Faturamento

Fonte: Elaborada pelo autor

\begin{tabular}{|l|c|c|c|}
\hline \multicolumn{1}{|c|}{ Tipo } & Pessimista & Esperado & Otimista \\
\hline Operacional de Vendas & $7 \%$ & $7 \%$ & $7 \%$ \\
\hline Marketing/Publicidade & $10 \%$ & $10 \%$ & $10 \%$ \\
\hline Administrativa & $9 \%$ & $9 \%$ & $9 \%$ \\
\hline
\end{tabular}

\subsubsection{Depreciação}

A depreciação foi considerada para todos os equipamentos adquiridos para a produção de cerveja. A vida útil para eles foi estipulada em 10 anos, e com isso a taxa de depreciação é de $10 \%$ ao ano. Isso significa que a cada ano o valor da capacidade produtiva diminui. A depreciação não está relacionada a uma saída de caixa, mas a perda de valor representa a diminuição da vida útil dos equipamentos e, consequentemente, um investimento que precisará ser refeito no futuro.

\subsection{Custo de Capital}

Para estimar a viabilidade de um projeto é necessário entender como os recursos inicialmente investidos serão captados. A teoria do custo de capital já foi explicada anteriormente, e agora será aplicado à projeção, para que os fluxos de caixa da cervejaria sejam descontados ao longo do tempo e tornem-se comparáveis entre si.

A partir disso, serão discutidos os métodos de cálculo para o custo do capital próprio (CAPM) e o de terceiros, para chegar à custo médio ponderado de capital a partir da proporção de investimento entre as duas fontes de capital.

\subsubsection{Custo do Capital Próprio (CAPM)}

Considerando que o capital investido no projeto em questão poderia estar sendo aplicado em qualquer título ou fundo a nível mundial, foram utilizadas 
premissas americanas para o cálculo do CAPM. Indicadores como a taxa livre de risco, retorno de mercado e beta desalavancado (não considera dívidas das empresas do setor) são dados americanos e convertidos a partir das taxas de inflação dos países.

Assim, de acordo com Damodaran (2017), a taxa livre de risco nos EUA com base nos títulos do tesouro americano de 10 anos é de 5,03\% ao ano. O retorno S\&P 500 que equivale ao retorno de mercado é de 8,64\% ao ano. É importante afirmar que este é um valor médio considerando o mesmo período de 10 anos do título do tesouro, para que os retornos sejam comparáveis entre si. Por fim, para o beta desalavancado foi considerada a média entre setores com maior semelhança em relação ao mercado de cervejas artesanais. Os dois setores em questão são os de bebidas alcoólicas e vendas em varejo. Os valores são 0,63 e 0,8 respectivamente. Isso quer dizer que ambos são setores menos voláteis em comparação com a média do mercado.

Para realavancar o beta de acordo com a dívida do empreendimento em questão, deve-se considerar a relação entre a dívida e o patrimônio líquido. Assim, considerando a premissa de que o capital próprio representa $30 \%$ do investimento, esta razão é igual a 2,33. Portanto, como neste caso a tributação é através do sistema Simples Nacional, não há benefício fiscal visto que o desconto é feito direto sobre a receita bruta, o beta realavancado é igual a 2,38 e pode ser expresso por:

$$
\beta \text { realavancado }=\beta \text { desalavancado } x\left(1+\frac{D}{E}\right)
$$

Onde:

$\mathrm{D}$ = Dívida

$\mathrm{E}=$ Patrimônio Líquido

A partir da fórmula do CAPM e os dados americanos descritos anteriormente, é possível chegar ao seu valor final. Assim, o CAPM é igual a $13,63 \%$. Entretanto, ainda é preciso fazer a conversão de dólares para reais. Para isso, são utilizadas as taxas de inflação nos dois países, de forma que a taxa seja multiplicada pelo índice:

$$
\text { Índice de conversão }=\frac{\left(1+\pi_{B R}\right)}{\left(1+\pi_{E U A}\right)}
$$

Onde:

$$
\begin{aligned}
& \Pi_{B R}=\text { Inflação no Brasil } \\
& \Pi_{E U A}=\text { Inflação nos Estados Unidos }
\end{aligned}
$$


De acordo com um artigo do Valor Econômico (2017), a expectativa de inflação para o Brasil em 2017 segundo o Boletim Focus é 3,51\% no ano. Nos EUA, por outro lado, a expectativa do Federal Reserve (Fed, Banco Central Americano) no mesmo período é de 1,6\%, segundo artigo publicado pelo Estadão (2017). Assim, chega-se ao índice de conversão de 1,02. O CAPM convertido para reais é, portanto, $13,89 \%$. Esta taxa será utilizada em todos os cenários. A tabela 11 resume este cálculo:

Tabela 11: Custo do Capital Próprio (Modelo CAPM)

Fonte: Elaborada pelo autor

\begin{tabular}{|l|c|}
\hline \multicolumn{1}{|c|}{ Índice } & Valor \\
\hline Risk Free EUA (10 year Tbonds a.a.) & $5,03 \%$ \\
\hline Beta Damodaran Realavancado & 2,38 \\
\hline S\&P 500 (a.a.) & $8,64 \%$ \\
\hline Ke US\$ (a.a.) & $13,63 \%$ \\
\hline Índice de Conversão US\$ -> R\$ & 1,02 \\
\hline Ke RȘ (a.a.) & $\mathbf{1 3 , 8 9 \%}$ \\
\hline
\end{tabular}

\subsubsection{Custo do Capital de Terceiros}

O capital de terceiros corresponde a $70 \%$ do investimento inicial, montante equivalente a $R \$ 701.960,00$. Considerando que este valor será financiado no BNDES, uma linha de crédito que o projeto se enquadra é o BNDES Finame - BK Aquisição e Comercialização.

De acordo com as regras estabelecidas no site do BNDES (2017), é possível ter participação de até $80 \%$ e pagamento em até 10 anos, com até 2 anos de carência. Os juros cobrados são as taxas de juros de longo prazo de 7,0\% ao ano referente ao custo financeiro, do BNDES de 2,1\% e outra negociada diretamente com o agente financeiro. Para efeitos de projeção, esta taxa será considerada $0,9 \%$ e o custo do capital de terceiros, portanto, igual a $10 \%$ ao ano.

\subsubsection{Custo Médio Ponderado de Capital}

O custo de capital (WACC) é a média ponderada entre o custo de capital próprio e de terceiros, levando em consideração a participação de capital de cada uma das partes. No caso em questão, a microcervejaria terá 30\% de patrimônio líquido e os $70 \%$ restantes captados junto ao BNDES. Assim, é possível concluir que o WACC será igual a 11,17\%. 
Para ser comparável aos fluxos de caixa, entretanto, é preciso desconsiderar a inflação atrelada aos custos de capital uma vez que não são considerados nos fluxos de caixa. O valor final do WACC sem a inflação é, portanto, $10,79 \%$, que é o mesmo para todos os cenários.

\subsection{Projeção de Resultados}

Após a projeção de receitas, custos, despesas e WACC, é possível estimar os fluxos de caixa da cervejaria. Os indicadores utilizados para discutir sobre a viabilidade do negócio são um reflexo do comportamento destes fluxos de caixa ao longo do tempo, como já foi discorrido anteriormente.

\subsubsection{Fluxo de Caixa dos Ativos}

Existem algumas formas de medir o fluxo de caixa de uma empresa, porém para o estudo da viabilidade econômica é importante utilizar o fluxo de caixa dos ativos (FCA). Diferente de outras interpretações, como o fluxo de caixa operacional, o FCA considera também os gastos líquidos de capital ao longo do tempo e a variação do capital de giro. O cálculo do FCA leva em consideração apenas custos, despesas e investimentos operacionais. Portanto, os juros pagos em função do capital de terceiros não devem ser considerados.

Além de observar o valor do FCA, é preciso descontá-lo para ser comparado com valores presentes. Em outras palavras, os fluxos de hoje não são equivalentes aos futuros, e a taxa de desconto é responsável pela sua conversão ao longo do tempo, e o fluxo de caixa dos ativos descontado (FCAD) é o resultado. A soma dos FCAD, por sua vez, é o FCAD acumulado, considerando o investimento inicial e a soma de todos os fluxos subsequentes. A tabela 12 resume a formação do FCA, e os resultados estimados para cada um dos cenários estão expostos na figura 7: 
Tabela 12: Composição do FCA no Cenário Esperado

Fonte: Elaborada pelo autor

\begin{tabular}{|c|c|c|c|c|c|}
\hline & Ano 1 & Ano 2 & Ano 3 & Ano 4 & Ano 5 \\
\hline Receita Vendas & $\mathrm{R} \$ 235.842,24$ & $\mathrm{R} \$ 303.915,66$ & $\mathrm{R} \$ 391.637,76$ & $\mathrm{R} \$ 504.679,94$ & $\mathrm{R} \$ \mathbf{6 5 0 . 3 5 0 , 5 8}$ \\
\hline Receita Aluguel & $\mathrm{R} \$ 197.508,48$ & $\mathrm{R} \$ 179.575,03$ & $\mathrm{R} \$ 143.642,01$ & $\mathrm{R} \$ 97.349,10$ & $\mathrm{R} \$ 341.729,70$ \\
\hline Receita Bruta & $\mathrm{RS \$} 433.350,72$ & $\mathrm{RS} \mathbf{4 8 3 . 4 9 0 , 6 9}$ & RȘ 535.279,77 & $\mathrm{RSS} 602.029,05$ & $\mathrm{RSS} 992.080,28$ \\
\hline Taxa \% Simples Nacional & $10,00 \%$ & $10,00 \%$ & $10,00 \%$ & $10,00 \%$ & $11,20 \%$ \\
\hline Desconto Previsto & $\mathrm{R} \$ 13.860,00$ & $\mathrm{R} \$ 13.860,00$ & $\mathrm{R} \$ 13.860,00$ & $\mathrm{R} \$ 13.860,00$ & $\mathrm{R} \$ 22.500,00$ \\
\hline Tributação Simples & R\$ $29.475,07$ & $\mathrm{R} \$ \quad 34.489,07$ & $\mathrm{R} \$ \quad 39.667,98$ & $\begin{array}{ll}\text { R\$ } & 46.342,90 \\
\end{array}$ & $\mathrm{R} \$ \quad 88.612,99$ \\
\hline Receita Líquida & $\mathrm{R} \$ \mathbf{4 0 3 . 8 7 5 , 6 5}$ & $\mathrm{R} \$ \mathbf{4} 49.001,62$ & RȘ 495.611,79 & $R \$ 555.686,14$ & $\mathrm{R} \$ 903.467,29$ \\
\hline CMV & $\mathrm{R} \$ 116.657,68$ & $\mathrm{R} \$ 150.329,71$ & $\mathrm{R} \$ 193.720,82$ & $\mathrm{R} \$ 249.636,33$ & $\mathrm{R} \$ 321.691,27$ \\
\hline Lucro Bruto & $\mathrm{R} \$ \mathbf{2 8 7 . 2 1 7 , 9 7}$ & $\mathrm{R} \$ 298.671,91$ & $R \$ 301.890,97$ & $\mathrm{R} \$ \mathbf{3 0 6 . 0 4 9 , 8 1}$ & $\mathrm{R} \$ \mathbf{5 8 1 . 7 7 6 , 0 2}$ \\
\hline Desp. Oper. Vendas & $\mathrm{R} \$ \mathbf{3} \quad 30.334,55$ & $\mathrm{R} \$ 33.844,35$ & $\mathrm{R} \$ 37.469,58$ & $\mathrm{R} \$ \mathbf{4} \quad 42.142,03$ & $\mathrm{R} \$ \quad 69.445,62$ \\
\hline MKT/Publi & R\$ $23.584,22$ & $\mathrm{R} \$ 30.391,57$ & $\mathrm{R} \$ 39.163,78$ & $\mathrm{R} \$ \quad 50.467,99$ & $\mathrm{R} \$ \quad 65.035,06$ \\
\hline Desp Adm. & $\mathrm{R} \$ \mathbf{3 9 . 0 0 1 , 5 6}$ & $\begin{array}{ll}\mathrm{R} \$ & 43.514,16 \\
\end{array}$ & $\mathrm{RS} \quad 48.175,18$ & RS $54.182,61$ & $\mathrm{R} \$ \mathbf{8 9 . 2 8 7 , 2 3}$ \\
\hline EBITDA & $\mathrm{R} \$ \mathbf{1 9 4 . 2 9 7 , 6 3}$ & $R \$ 190.921,84$ & $\mathrm{R} \$ \mathbf{1 7 7 . 0 8 2 , 4 3}$ & $R \$ 159.257,17$ & $\mathrm{RS} 358.008,12$ \\
\hline Depreciação & $\mathrm{R} \$ \quad 55.280,00$ & $\mathrm{R} \$ \quad 55.280,00$ & $\mathrm{R} \$ \mathbf{5} 5.280,00$ & $\mathrm{R} \$ \quad 55.280,00$ & $\mathrm{R} \$ \quad 65.280,00$ \\
\hline EBIT & $\mathrm{R} \$ \mathbf{1 3 9 . 0 1 7 , 6 3}$ & $\mathrm{RS} 135.641,84$ & $\mathrm{R} \$ \mathbf{1 2 1 . 8 0 2 , 4 3}$ & RS\$ 103.977,17 & $\mathrm{R} \$ \mathbf{2 9 2 . 7 2 8 , 1 2}$ \\
\hline $\mathrm{FCO}$ & $\mathrm{R} \$ 194.297,63$ & $\mathrm{R} \$ 190.921,84$ & $\mathrm{R} \$ 177.082,43$ & $\mathrm{R} \$ 159.257,17$ & $\mathrm{R} \$ 358.008,12$ \\
\hline FCO Descontado & R\$ 174.779,88 & RS\$ 154.491,11 & $\mathrm{RS} 128.898,34$ & R\$ 104.278,51 & $\mathrm{R} \$ 210.868,95$ \\
\hline Variação de capital de Giro & $\mathrm{R} \$$ & R\$ $50.000,00$ & $\mathrm{R} \$ \quad 50.000,00$ & $\mathrm{RS} \quad 50.000,00$ & $\mathrm{R} \$ \quad 50.000,00$ \\
\hline Gastos Líquidos de Capital & $\mathrm{R} \$ \mathbf{5} 55.280,00$ & $\mathrm{R} \$ 55.280,00$ & $\mathrm{R} \$ \mathbf{5} 55.280,00$ & $\mathrm{R} \$ \mathbf{5} 5.280,00$ & $\mathrm{R} \$ 165.280,00$ \\
\hline FCA & $\mathrm{R} \$ 139.017,63$ & $\mathrm{R} \$ 135.641,84$ & $\mathrm{R} \$ 121.802,43$ & $\mathrm{R} \$ 103.977,17$ & $\mathrm{R} \$ 192.728,12$ \\
\hline
\end{tabular}

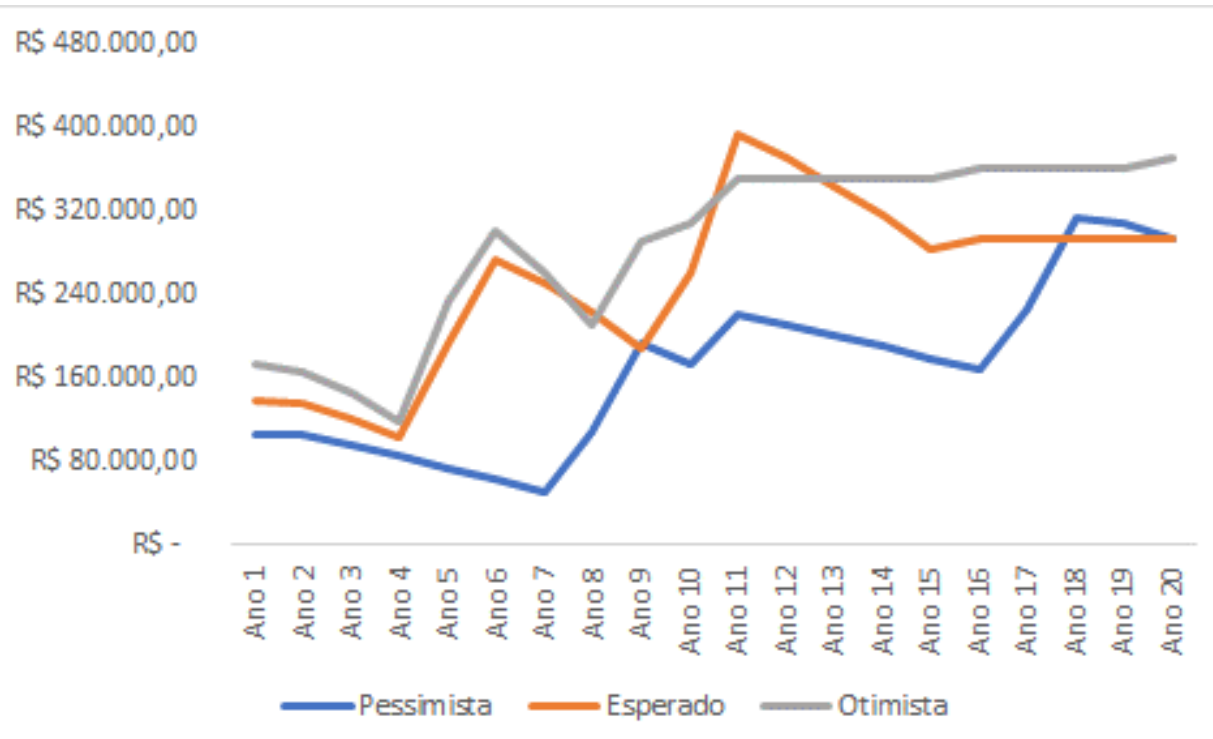

Figura 7: Evolução do Fluxo de Caixa dos Ativos entre os Cenários

Fonte: Elaborada pelo autor

\subsubsection{Indicadores Financeiros}

A partir das informações acima, é possível calcular indicadores de viabilidade, como o valor presente líquido (VPL), taxa interna de retorno (TIR) e tempo de payback em cada um dos cenários. A análise sobre a viabilidade levará em conta principalmente o resultado destes indicadores, além de outras condições 
importantes em termos de premissas assumidas. A tabela 13 a seguir consolida todos os indicadores:

Tabela 13: Indicadores de Viabilidade Econômica

Fonte: Elaborada pelo autor

\begin{tabular}{|c|c|c|c|}
\hline Indicador & Pessimista & Esperado & Otimista \\
\hline VPL & $66.852,82$ & $\mathrm{R} \$ \mathbf{7 4 0 . 5 2 3 , 3 2}$ & $\mathrm{R} \$ 980.081,05$ \\
\hline TIR & $11,15 \%$ & $13,89 \%$ & $14,63 \%$ \\
\hline Payback & $10 \cong$ ano & 70 ano & 60 ano \\
\hline Payback Desc. & 190 ano & $10 \%$ ano & 90 ano \\
\hline
\end{tabular}

Dadas estas condições, o negócio pode ser considerado viável, porém pouco rentável. O VPL modesto, TIR próxima da taxa de desconto e payback em torno de 10 anos não contribuem para uma perspectiva promissora. Através do fluxo de caixa descontado acumulado, que determina o tempo de payback e traduz a rentabilidade do negócio, a figura 8 demonstra a relação entre investimento e retorno:

\section{R\$ $1.500 .000,00$ \\ R\$ $1.000 .000,00$ \\ R\$ $500.000,00$ \\ RS - \\ -R\$ $500.000,00$ \\ - R\$ $1.000 .000,00$
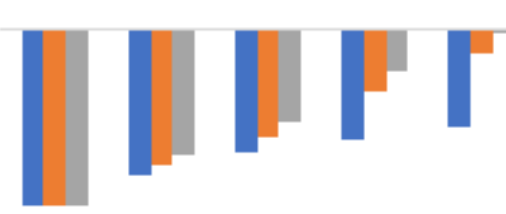 \\ Ano 0 Ano 2 Ano 4 Ano 6 Ano 8 Ano 10 Ano 12 Ano 14 Ano 16 Ano 18 Ano 20 \\ - Pessimista nEsperado notimista}

Figura 8: Evolução do FCA Descontado Acumulado entre os Cenários

Fonte: Elaborada pelo autor

A partir desta constatação, foi idealizada uma forma de rentabilizar mais o negócio, a partir de uma mudança estratégica. Ao invés de produzir cerveja e alugar o espaço para outras cervejarias, a única fonte de receita no cenário alternativo é o aluguel. 


\subsubsection{Cenário Alternativo}

Considerando os custos de produção e, consequentemente, as margens observadas entre as diferentes fontes de receita, a criação de uma situação alternativa na qual a produção seja zero pode significar maior rentabilidade para o negócio. Neste cenário o empreendimento passa a funcionar apenas como fábrica, oferecendo a sua capacidade produtiva em forma de aluguel para outras cervejarias.

Esta mudança impacta a motivação inicial de montar uma microcervejaria artesanal, entretanto pode significar um investimento mais rentável financeiramente dentro do mesmo mercado. Ao invés de ser um produtor que comercializa ao público, é um fornecedor que viabiliza a produção de outras cervejarias.

Outra característica importante é que o investimento feito a partir do crescimento da demanda ao longo do tempo nos demais cenários é realizado inicialmente. Isso afeta o montante da dívida da empresa, mas não o custo de capital, visto que são mantidas as premissas de capital $70 \%$ próprio e $30 \%$ de terceiros.

Os resultados deste cenário indicam que de fato a mudança no modelo de negócios pode ser positiva para empresa. Com a receita apenas do aluguel, sem arcar com custo de mercadorias vendidas, a rentabilidade do empreendimento apresenta melhora, como pode ser observado na tabela 14 e figura 9:

Tabela 14: Indicadores de Viabilidade Econômica com Cenário Alternativo

Fonte: Elaborada pelo autor

\begin{tabular}{|c|c|c|c|c|}
\hline Indicador & Pessimista & Esperado & Otimista & Alternativo \\
\hline VPL & $66.852,82$ & $\mathrm{R} \$ \quad 740.523,32$ & $\mathrm{R} \$ \quad 980.081,05$ & $\mathrm{RS} 1.561 .990,27$ \\
\hline TIR & $11,15 \%$ & $13,89 \%$ & $14,63 \%$ & $16,11 \%$ \\
\hline Payback & $10 \%$ ano & 70 ano & 60 ano & 40 ano \\
\hline Payback Desc. & $19 \circ$ ano & 10 ano & 9o ano & 50 ano \\
\hline
\end{tabular}


R\$ $2.000 .000,00$

R\$ $1.500 .000,00$

R\$ $1.000 .000,00$

RS $500.000,00$

RS -

$-R \$ 500.000,00$

-R\$ $1.000 .000,00$

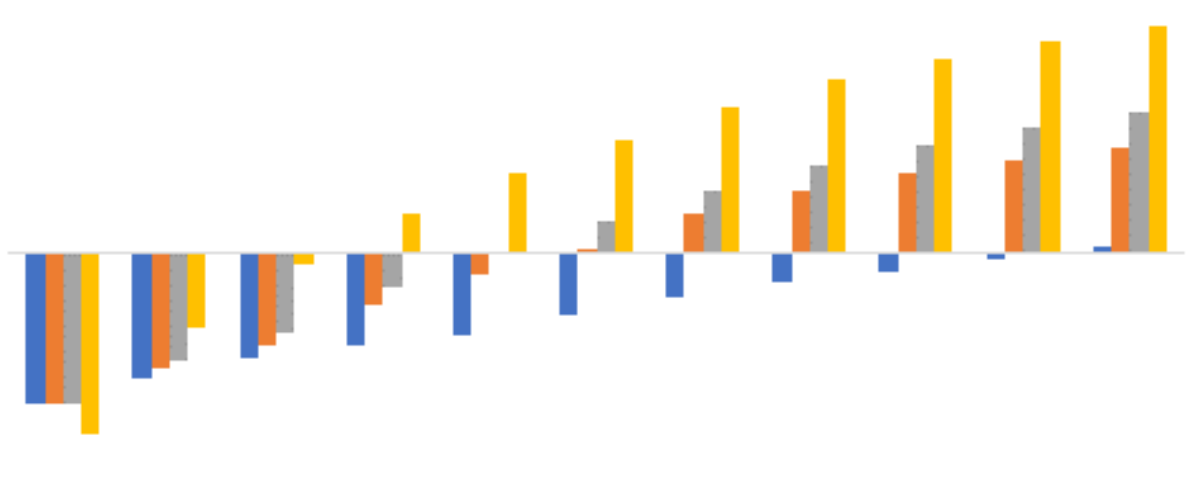

-R\$ $1.500 .000,00$

Ano 0 Ano 2 Ano 4 Ano 6 Ano 8 Ano 10 Ano 12 Ano 14 Ano 16 Ano 18 Ano 20

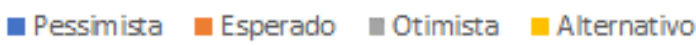

Figura 9: Comparação FCA Desc. Acumulado com Cenário Alternativo

Fonte: Elaborada pelo autor 


\section{Conclusões e Recomendações para Novos Estudos}

A partir das premissas de dados e perspectivas para o futuro do mercado cervejeiro no Brasil, foram desenvolvidas análises para determinar a viabilidade econômica de uma microcervejaria artesanal ao longo dos capítulos anteriores. $\mathrm{O}$ crescimento do mercado e o preço médio de venda são oportunidades observadas, porém os altos custos envolvidos para instalação da capacidade de produção e a própria operação contribuem para a diminuição das margens e retorno financeiro.

Como conclusão, é possível afirmar que o negócio possui indicadores positivos no que diz respeito à sua viabilidade. Apesar disso, apresenta condições incertas para a operação e, consequentemente, seus resultados. Em outras palavras, dado o risco, o retorno e o montante a ser investido, esta opção de investimento pode não ser indicada pela perspectiva financeira.

O principal fator que ilustra esta questão é que, mesmo com um período de projeção de 20 anos, o VPL não ultrapassa o valor investido inicialmente nos cenários pessimista, esperado e otimista. Isso demonstra a dificuldade para rentabilizar este tipo de negócio, e a principal causa é o alto investimento necessário.

Outra análise importante é que, no cenário pessimista, o VPL é próximo de zero, a TIR é menor do que a taxa de desconto e o payback descontado acontece apenas no vigésimo ano. Nestas condições, mesmo tratando-se de um projeto viável, o investimento em outras oportunidades do mercado é, na média, mais rentável em termos financeiros.

O cenário alternativo, por outro lado, apresenta resultados mais consistentes. Além de possuir alto VPL quando comparado com os demais cenários, possui a maior taxa interna de retorno e o menor payback. Isso indica que montar a estrutura e alugar para outras cervejarias pode ser financeiramente mais viável do que produzir e comercializar o próprio produto. Em outras palavras, apresentar-se como uma solução para o alto custo da capacidade de produção, que é um problema comum de todo o mercado, é mais rentável do que ser um pequeno competidor no mercado de cervejas artesanais. 
Para outros trabalhos, a sugestão é estudar a viabilidade de iniciar a operação de uma cervejaria artesanal sem investir em capacidade de produção, operando a partir do aluguel de capacidade produtiva, como a que foi proposta como fonte de receita adicional neste trabalho. O objetivo deste trabalho futuro seria identificar momento ideal para uma microcervejaria investir em capacidade de produção própria, sem se prejudicar financeiramente. 


\section{Referências Bibliográficas}

Banco Nacional do Desenvolvimento. O setor de bebidas no Brasil. Rio de Janeiro, 2014 Disponível em: < http://www.bndes.gov.br/>. Acesso em: 10 de junho. 2017.

Associação Brasileira da Indústria da Cerveja. Anuário 2016. Rio de Janeiro, 2016 Disponível em: < http://www.cervbrasil.org.br/>. Acesso em: 15 de maio. 2017.

Guia do Gourmet. Cerveja Artesanal. Rio de Janeiro, 2016 Disponível em: < http://www.guiadogourmet.com.br/cerveja-artesanal/>. Acesso em: 20 de maio. 2017.

Revista Food Magazine. A Hora e a Vez das Cervejas Artesanais. Rio de Janeiro, 2015 Disponível em: < http://www.foodmagazine.com.br/>. Acesso em: 17 de abril. 2017.

Sebrae. Microcervejarias. Rio de Janeiro, 2016 Disponível em: < http://www.bibliotecas.sebrae.org.br/>. Acesso em: 27 de abril. 2017.

Instituto da Cerveja Brasil. Infográfico - Mercado Brasileiro de Cervejas Artesanais. Rio de Janeiro, 2016 Disponível em: < http://www.institutodacerveja.com.br/>. Acesso em: 13 de março. 2017.

Mestre-Cervejeiro.com. Por que cervejas artesanais são mais caras: Produção. Rio de Janeiro, 2014 Disponível em: < http://www.mestrecervejeiro.com/>. Acesso em: 18 de outubro. 2017.

Revista Beer Art. $60 \%$ das microcervejarias vão aderir ao Simples, prevê Abracerva. Rio de Janeiro, 2016 Disponível em: < http://www.revistabeerart.com/>. Acesso em: 07 de janeiro. 2017.

Mestre-Cervejeiro.com. Por que cervejas artesanais são mais caras: Impostos. Rio de Janeiro, 2014 Disponível em: < http://www.mestrecervejeiro.com/>. Acesso em: 18 de outubro. 2017.

Bradesco. Indústria de Bebidas. Rio de Janeiro, 2017 Disponível em: < http://www.economiaemdia.com.br/>. Acesso em: 03 de julho. 2017.

DE ARAUJO, Guilherme Albertão. APURAÇÃO DA MARGEM DE CONTRIBUIÇÃO NA MICROCERVEJARIA GOLE MÁGICO. Negócios e Talentos, v. 12, n. 1, 2015.

DE MORAES TOSTES, Lucas Rodrigues. INSTRUMENTAÇÃO E CONTROLE DO PROCESSO DE PRODUÇÃO DE UMA MICROCERVEJARIA. 2015. Tese de Doutorado. Universidade Federal do Rio de Janeiro.

Instituto da Cerveja Brasil. Sommelieria e Educação Cervejeira, 2017. Rio de Janeiro, 2017. Material de estudo disponibilizado pela instituição.

MARTINS, E [et al]. Métodos de avaliação utilizados pelos profissionais de investimento. Revista UnB Contábil da Unniversidade de Brasília, Brasília, 2008.

CAIO GALDI, Fernando; CAMPANHARO TEIXEIRA, Aridelmo José; BROEDEL LOPES, Alexsandro. Análise empírica de modelos de valuation no ambiente brasileiro: fluxo de caixa descontado versus modelo de Ohlson (RIV). Revista 
Contabilidade \& Finanças-USP, v. 19, n. 47, 2008.

ROSS, S; WESTERFIELD, R; JORDAN, B. Fundamentos de administração financeira. Tradução de Leonardo Zilio e Rafaela Guimarães Barbosa. 9.ed. Porto Alegre: AMGH, 2013.

GITMAN, J. L. Princípios de administração financeira. Tradução de Allan Vidigal Hastings. 12.ed. São Paulo: Pearson Prentice Hall, 2010.

COPELAND, T; KOLLER, T; MURRIN, J. Avaliação de empresas - Valuation: calculando e gerenciando o valor das empresas. 3.ed. São Paulo: Pearson Makron Books, 2002.

O Globo. Fábrica de cerveja em Niterói produzirá rótulos de cerveja independentes. Rio de Janeiro, 2017. Disponível em: $<$ https://oglobo.globo.com/rio/bairros/fabrica-de-cerveja-em-niteroi-produzirarotulos-independentes-20945777>. Acesso em: 24 de outubro 2017.

Jornal Contábil. Simples Nacional 2018: Confira as novas tabelas e limites. Rio de Janeiro, 2017. Disponível em: < https://www.jornalcontabil.com.br/simplesnacional-2018-confira-as-novas-tabelas-e-limites > . Acesso em: 02 de setembro 2017.

Jornal Contábil. Simples Nacional 2018: Confira as novas tabelas e limites. Rio de Janeiro, 2017. Disponível em: < https://www.jornalcontabil.com.br/simplesnacional-2018-confira-as-novas-tabelas-e-limites $>$. Acesso em: 02 de setembro 2017.

DAMODARAN, A. Disponível em: <http://pages.stern.nyu.edu/ adamodar/>. Acesso em: 02 de setembro 2017.

Valor Econômico. Mercado espera inflação de 3,51\%, apura Focus. São Paulo, 2017. Disponível em: < http://www.valor.com.br/brasil/5087764/mercado-esperainflacao-de-351-em-2017-apura-focus>. Acesso em: 02 de setembro 2017.

BNDES. BNDES Finame - BK Aquisição e Comercialização. São Paulo, 2017. Disponível em: <https:// www.bndes.gov.br/wps/portal/site/home/financiamento/ produto/bndes-finame-bk-aquisicao-comercializacao>. Acesso em: 02 de setembro 2017. 
ANEXO 1 - Fluxo de Caixa dos Ativos (Cenário Esperado)

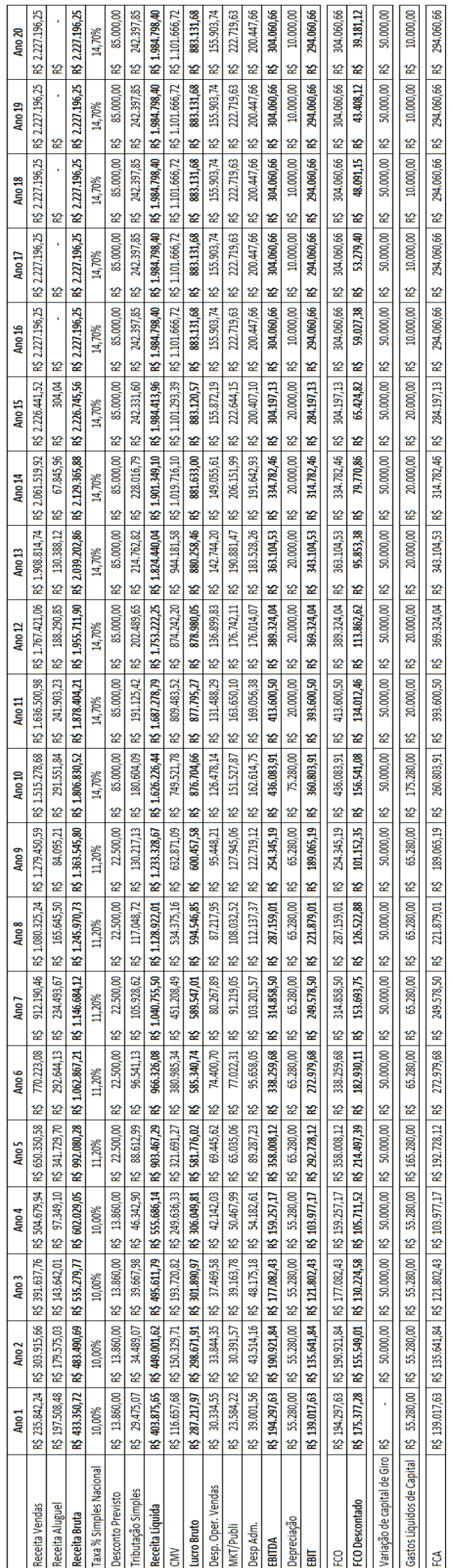


ANEXO 2 - Fluxo de Caixa dos Ativos (Cenário Pessimista)

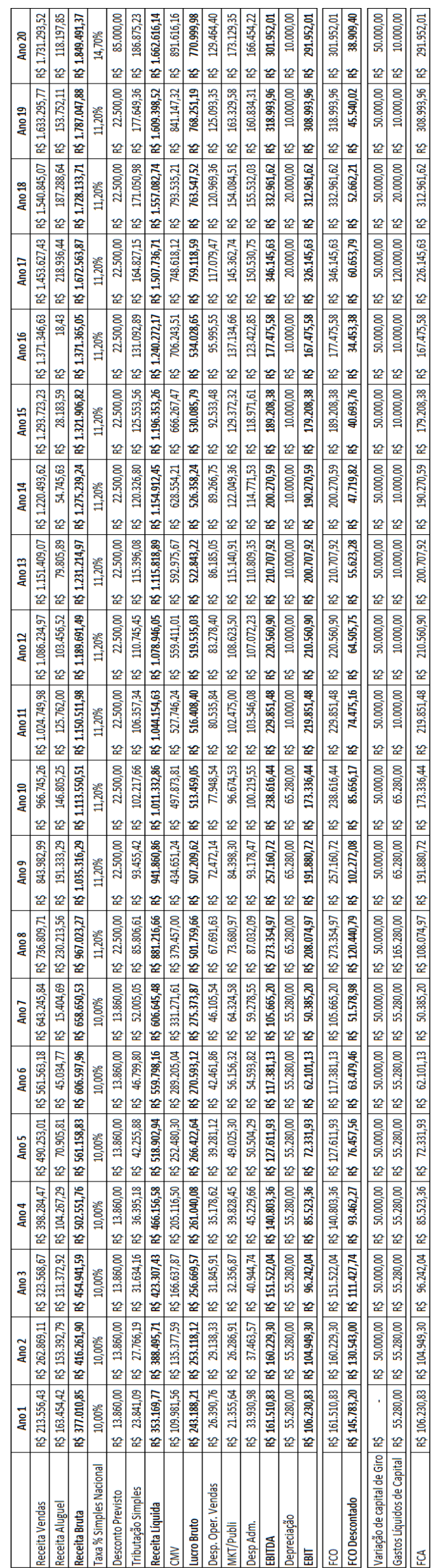


ANEXO 3 - Fluxo de Caixa dos Ativos (Cenário Otimista)

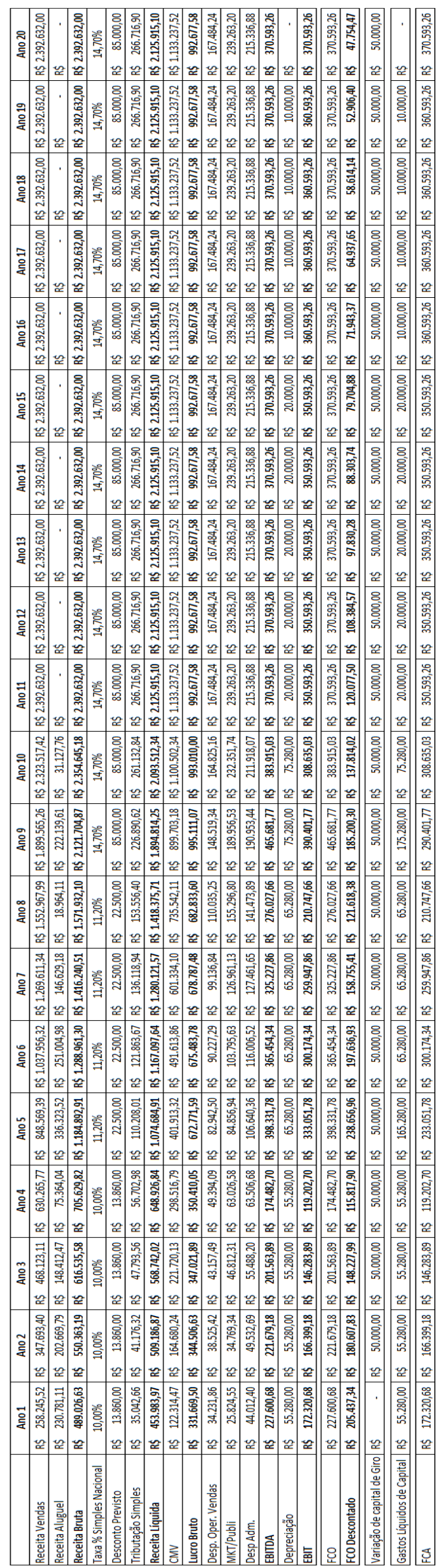

